\title{
Precedentes y sentido de la revolución de Ayutla*
}

Edmundo O'Gorman

El maestro O'Gorman recapitula sobre el Plan de Ayutla y su significado: hacer posible la reforma, pero no contra la historia, sino con ella.

\section{Propósitos}

A Arturo Amaiz y Freg

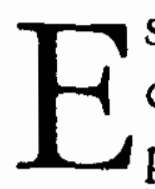

ste mes de marzo de 1954 nos convoca a celebrar con júbilo el primer cumplesiglos del Plan de Ayutla. Pero, ¿qué es, en efecto, lo que así queremos honrar? De buenas a primeras, no parece justificado el tributo: un oscuro militar, el coronel Florencio Villarreal, enriquece con un pronunciamiento más el largo inventario de asonadas: la triste estela de la marcha del país desde que su nave rompió amarras con España. De Dolores se llega peligrosamente a Ayutla por los desfiladeros turbulentos del hábito de la rebelión; y la circunstancia de merecer Ayutla el número veintitantos de las convulsiones políticas acaecidas en sólo medio siglo de vida independiente, más bien parece recomendar el pudor de un olvido discreto que no la algarabía del aplauso. Es evidente, sin embargo, que la decantación del juicio histórico ha destacado a Ayutla como luminosa señal en el panorama de nuestro pasado. Es una rebelión, sí; pero es la rebelión epónima, se

- Este ensayo aparecí como uno en la serie de estudios que, bajo el título Plan de Ayritla. Conmemoración de su primer centenario, publicó la Facultad de Derecho de la UNAM, en México, D.F., Talleres de Impresiones Modernas, 11 de diciembre de 1954. [La presente versión fue tomada de la obra de O'Gorman que la Universidad Veracruzana publicó en 1960 con el tírulo Seis estudios bistóricos de tema mexicano. E.]. 
dice, que marca la frontera entre las sombras y el día históricos de México. Se afirma, en efecto, que en Ayutla se sembró la semilla de la reforma fecunda y que, pues el vástago es tan ilustre, justo es que nuestra gratitud rememore los orígenes. Mas he ahi, precisamente, la cuestión que inquieta y que nos mueve a escribir estas páginas, porque ipodemos en conciencia adherirnos incondicionalmente a esa interpretación? ¿No, acaso, el reformismo liberal hunde sus raíces más allá de Ayutla? ¿No acaso, también, después deesa revolución pudo coronar la bandera conservadora a un emperador en México? ¿No acaso, por último, la reforma triunfante acabó en unos poquitos años por convertirse en científica reacción conservadora y terrateniente? Bien se columbra: mientras más nos alejamos de la rutina aprendida en las escuelas oficiales, Ayutla parece perder su lugar en la perspectiva canonizada, para presentarse como un nudo más en la complicada trama de un proceso que, antes y después, es mezcla de sombra y de luz, de buenas intenciones y de demagogia. Quizá sí; quizá Ayutla sea una encrucijada significativa que le muda el signo al toma y daca del poder en el juego de los partidos y de las ambiciones. Pero si así es, hagamos el descubrimiento por nuestra parte, en lugar de aceptar sin discrimen la santificación oficial. Es muy cómodo hacerse dueño del nombre de liberal subiéndose al carro de las interpretaciones hechas; pero quien de veras aspire aún hoy en día a $\tan$ alto honor debe tratar de merecerlo de algún modo: con sus actos y con su inteligencia; y si alguna es tarea liberal, es la del historiador que se rehusa a convertir en dogma la sentencia de sus predecesores, por más que le inclinen el corazón. El centenario que ahora se cumple y nos convoca, brinda esa oportunidad; nos invita, en efecto a reflexionar, con motivo de aquel plan de rebeldia que hace un siglo se proclamó en Ayutla, sobre la confusa marcha del liberalismo mexicano y sobre sus progresos y sus caídas: especie de examen de conciencia histórico, siempre la mejor celebración posible. Porque la historia, como el catecismo, nos conmina a confesarnos por lo menos una vez en cada siglo. Pongamos, pues, en saludable entredicho provisional nuestro entusiasmo conmemorativo, y volviendo la mirada con una cierta ingenuidad hacia los acontecimientos mexicanos de hace cien años, preguntemos por la intimidad de su razón de ser, la intimidad, en última instancia, de nuestro ser nacional. Situados así, en un terreno más profundo que aquel en que se finca la pura fama de la hermenéutica oficial, intentaremos mostrar que nuestra historia, por lo menos desde la insurgencia, es la de un pueblo atenazado por dos utopismos contrarios, por dos sueños en pugna, y que en la dialéctica de esa oposición encuentra el Plande Ayutla su perspectiva adecuada. Tratemos, entonces, de averiguar, primero, qué tiene de peculiar ese documento tan históricamente responsabilizado y qué tanto quiere recomendarse al aplauso; averigüemos, enseguida, cuál es, para nosotros, el sentido de la revolución cuya memoria nos congrega.

\section{La paradoja de Ayutla}

Hemos sugerido que cierta ingenuidad es actitud propicia para acercarnos al 


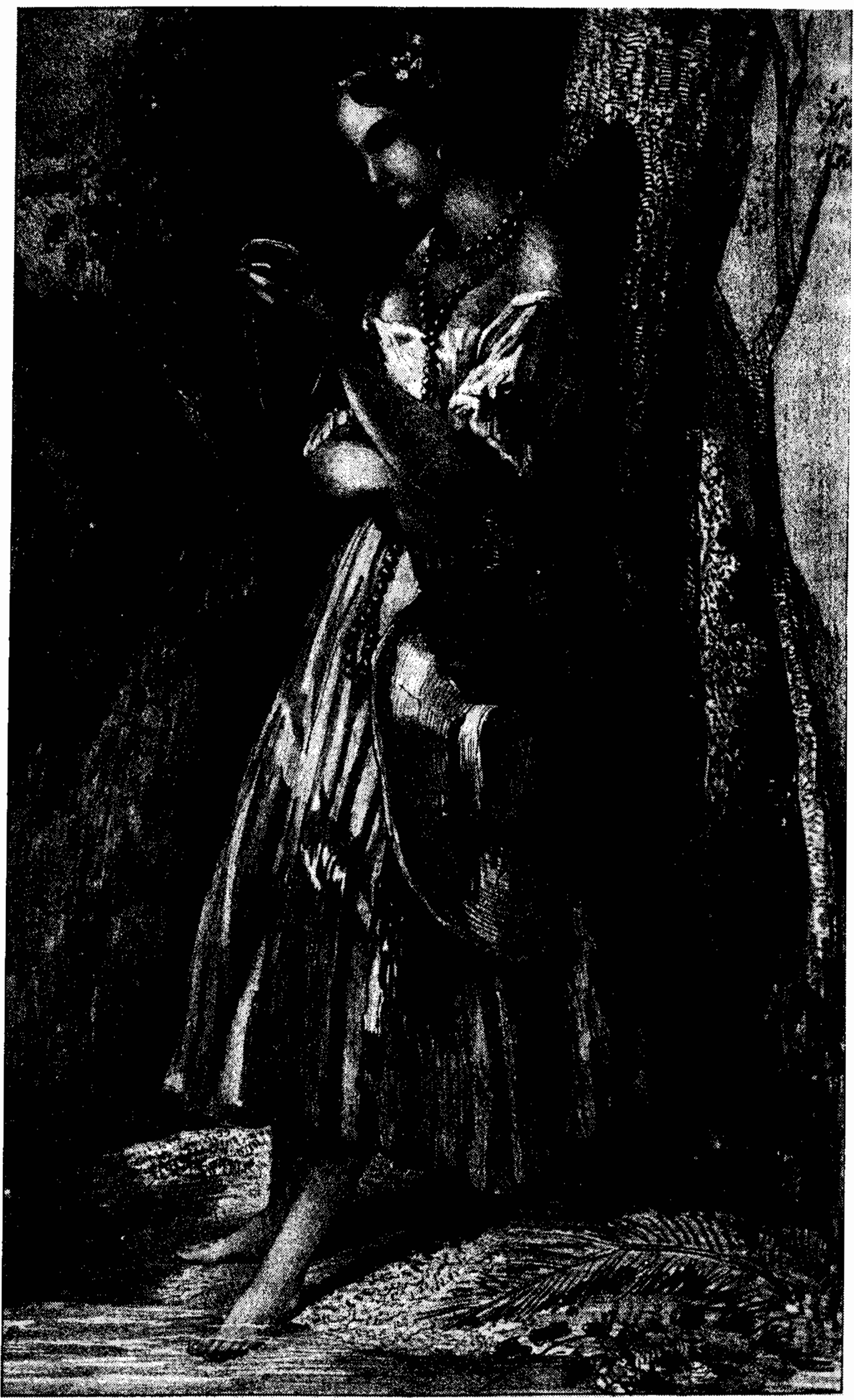


pasado; y es que sólo así cabe el asombro, el fecundo pasmo de que habla el filósofo como disparadero de toda intelección. Y en efecto, el fruto no deja de manifestarse de inmediato, porque, visto el mucho ruido que ha suscitado la revolución de Ayutla, la lectura del plan que la inició nos deja en desconcierto. Es un documento tan abundante en trivialidades declamatorias sobre el celo por la libertad, sobre la abnegación patriótica y sobre aquello de derramar la última gota de sangre; un documento tan inundado de halagos demagógicos y tan colmado de resentimiento partidarista y de imprevisión política, que apenas se distingue de los muchos otros de su especie que lo precedieron. Sin embargo, el hecho es que el Plan de Ayutla ha despertado entre los historiadores el entusiasmo, y ese hecho pide una explicación.

Pues bien, veamos entonces ¿en qué consiste ese famoso plan? En primer lugar, es un llamamiento de rebeldía contra el gobierno de la república; una rebelión iniciada por un grupo del ejército nacional. Pero esto, bien lo sabemos, nada tiene de novedoso. Es, en segundo lugar, un ofrecimiento de constituir a la nación de un modo distinto al establecido una vez que la revolución hubiera triunfado. De esta manera, México se salvaría de tantos males como lo venían afligiendo y entraría por la senda del progreso y del bienestar. Pero, ciertamente, tales promesas ya se habian oído hasta el cansancio. Por último, es un plan que determinaba el modo en que el país sería gobernado mientras le llegaba su hora tan cercana de felicidad definitiva. Tampoco en esto revela el documento ninguna originalidad espe- cial que lo recomiende de extraordinario. Se decía que el general en jefe de las fuerzas revolucionarias convocaría, a raíz del triunfo, una especie de congreso mínimó encargado de elegir un presidente interino de la república, cuya misión fundamental sería convocar, a su vez, a un congreso extraordinario constituyente. Éste, con notoria violación de su soberania iba a nacer con la obligación de darle al país la forma de república representativa popular, manera de prometer que México no se constituiría en imperio y de insinuar el regreso a la federación. Mientras esto podía llevarse a efecto, el presidente interino gobernaría con facultades poco menos que omnímodas, suponiéndose con más fe que la que autorizaba la experiencia que las emplearía sólo en bien de la patria. Se establecía sumariamente la manera en que se administrarían los estados, entre tanto el país quedaba debidamente constituido; se declaraba la protección al comercio y la abolición inmediata de algunas leyes particularmente odiosas, $y$ previo un demagógico halago al ejército como noble protector del orden y de las garantías, se prometió que el gobierno lo cuidaría y atendería debidamente. El ejército iba a ser el niño mimado del nuevo régimen. Tal es, en sustancia, el famoso Plan de Ayutla.

Ciertamente ese documento quedó en breve reformado en Acapulco (11 de marzo de 1854) por Comonfort quien, según reza el acta respectiva, se hallaba en el puerto "por una feliz casualidad", pero no por eso menos dispuesto al "sacrificio de tomar una parte activa en los sucesos políticos que iban a iniciar$\mathrm{se}^{n}$, y a cumplir "el deber sagrado de posponer su tranquilidad y sus intereses 
particulares al bienestar de sus compatriotas". La modificación principal consistió en suprimir la insinuación de la vuelta a la república federal. Los disidentes, decía Comonfort, no tenían, como buenos hijos de la patria, "ni la más remota idea de imponer condiciones a la soberana voluntad del país, restableciendo por la fuerza de las armas el sistema federal". El nuevo plan, pues, se limitó a declarar que "las instituciones liberales son las únicas que convienen al país"; pero se aclaró que semejante conveniencia no toleraba el régimen monárquico, calificado de "ridículo" y de "contrario a nuestro carácter y costumbres". Se aludía, claroestá, al proyecto del partido conservador de implantar en México una monarquía, y aun conviniendo en que sería ridícula y contraria a la idiosincrasia nacional, la verdad es que la aclaración no vulneraba menos la soberanía del Congreso Constituyente que la insinuación en favor del federalismo. Comonfort sabía que una monarquía no excluye necesariamente las instituciones liberales, y que, por lo tanto, si esas eran las que convenían a México, no había motivo justificado para privar al Congr io Constituyente de la libertad de pronur iarse en favor del régimen monárquico. La reforma al Plan de Ayutla responde, pues, a exigencias políticas de partido y no a puntos de doctrina, según pretendía hacerse aparecer. Pero conviene advertir que no sólo se conculcaba la voluntad de la representación nacional, sino que la reforma acusa claramente el temor fundado de que se llegara por la vía legal al establecimiento de la monarquía. El Plan de Comonfort estaba calculado como un dique contra semejante posibilidad, y éste es un punto sobre el cual conviene insistir un poco por su trascendencia. En efecto, hoy, después del desastre del segundo imperio, una monarquía nos parece ridícula; pero es preciso admitir que en 1854 ese tipo de gobierno se ofrecía a muchos como la solución adecuada para protegernos de los norteamericanos y como el régimen que pondría fin a las disensiones políticas del país. El solo nombre de Lucas Alamán garantiza el acierto de esa afirmación, porque a nadie conviene peor el epíteto de iluso, ni el de traidor tampoco, por más equivocada que pueda parecernos su política. Pero si esa prueba no bastase, allí está la existencia del segundo imperio como evidencia definitiva de que se le creyó plausible. No olvidemos que, al fin y al cabo, sólo unos pocos años separan al primer ensayo monárquico del movimiento de Ayutla, de tal manera que no parece aventurado creer que si Comonfort apostrofaba de ridícula la idea de una monarquía en México, lo hacía con el propósito combativo de desprestigiar un proyecto vigente en la conciencia de muchos mexicanos, y no en el sentido de mofa con que hoy podríamos hacerlo. Ya es tiempo de superar la visión jacobina oficial, que pretende explicar la acción del partido conservador como las maquinaciones de un pequeño grupo de hombres inteligentes y perversos, que supo imponer su voluntad al pueblo por medio de la fuerza y del engaño. La verdad parece ser la contraria; parece que las tendencius llamada: reaccion?. rias contaban entonze. $\&$, n un ma ${ }^{*}$ is apoyo en la voluntad general que las ideas liberales; pero esta circunstancia, que podría capitalizarse demagógicamente, sirve en realidad para mostrar 
que el lento y penoso triunfo del liberalismo entre nosotros, ha sido un notable progreso del convencimiento popular en la bondad de esa doctrina como base de la convivencia humana. Pese a mezquindades y personalismos en ambos bandos, se ofrece como más verdadero, es decir, como más justo, pensar que las luchas entre conservadores y liberales estuvieron animadas por una suficiente dosis de buena fe, como para poder entenderlas a la luz de una visión más penetrante de nuestra historia, que revela la pugna de los dos grandes sueños que han normado la marcha histórica de México como nación independiente.

Pero antes de abordar tan decisiva cuestión, debemos terminar el análisis de los textos que nos vienen ocupando, al poner de relieve una diferencia importante entre los planes de Ayutla y Acapulco y dos circunstancias significativas que les son comunes.

Por lo que toca a la diferencia, aludimos al punto concreto de la suma de poder con que iba a quedar investido el presidente interino que debería designar al triunfar la revolución. En efecto, si lo previsto a ese respecto en el Plan de Ayutla dejaba algunas dudas acerca de la amplitud de facultades de aquel magistrado, en el texto de Acapulco quedaron definitivamente disipadas: se dispuso que "sin más restricción que la de respetar inviolablemente las garantías individuales $^{n}$ (que, por otra parte, no quedaron especificadas), el presidente interino cuidaría de la seguridad e independencia de la nación y que podía "reformar todos los ramos de la administración pública" y "promover cuanto conduzca a la prosperidad, engrandecimiento y progreson de México. Es decir, salvo erigirse en emperador, el presidente podía hacer poco más o menos lo que le viniera en gana. Concedámosle la gracia a Comonfort de no suponer malévólamente que pensaba en sí mismo cuando dictóesa disposición; pero parece obvio, eso sí, que pensaba en la necesidad de poner al gobierno en manos de un hombre fuerte que pudiera mantener el orden público y conservar la paz, obrando sin las dilaciones y los trámites de las barreras legales. Y no otra cosa, en efecto, animaron los propósitos de Comonfort, cuando, encargado de la presidencia a raíz del triunfo revolucionario, pretendió gobernar con el Estatuto Orgánico de 1856. Lo paradójico fue que Comonfort, un liberal mode-rado, no supo o no quiso encarnar a ese hombre fuerte que él mismo había previsto, cosa que quizás lo honra, pero que acarreó inevitablemente su derrota personal. Sin embargo, la importancia decisiva del pensamiento de Comonfort consagrado en el Plan de Acapulco no es esa: es de mayor trascendencia que la evidenciada por los sucesos inmediatos. En efecto, la idea de erigir un "hombre fuerte $^{n}$ que contemplara los mecanismos legales políticos como estorbos en la tarea de gobernar al país, contenía el germen de una doctrina peligrosa y en teoría profundamente antiliberal, directamente opuesta al espíritu de la revolución de Ayutla. Los liberales se contagiaban del cáncer que combatían en los conservadores: en el seno de su partido había brotado la semilla de la dictadura con su justificación oportunista, que más tarde florecería magnífica en la persona del general Porfirio Díaz.

Por cuanto a las dos circunstancias significativas a que aludí como comunes 
a ambos planes, me refiero, en primer lugar, al silencio que se guardó tocante a las cuestiones religiosa y de fueros y privilegios del clero. No encontramos, ni el pro, ni el contra; no hay ni una sola palabra dedicada a unos problemas de tan subida importancia política en aquellos años; pero es evidente que el vacío intencionado y que se mostraba así, por una parte, el deseo de no sembrar alarma con alguna declaración expresa que pudiera interpretarse como hostilidad a las creencias católicas y por otra parte, la clara intención de poner los destinos políticos del país más allá del alcance de la Iglesia, cuyos intereses había uncido Alamán al carro del partido enemigo. Este silencio ominoso anuncia ya todo el programa anticlerical reformista de los años siguientes.

La otra circunstancia es aún más significativa para los efectos de nuestras consideraciones posteriores. Me refiero a un hecho que les presta a los dos documentos que analizamos una peculiaridad que los individualiza y es el hecho de que la rebelión que suscitaron fue, ante todo, un movimiento dirigido contra una persona; no fue, como habitualmente se enseña, una revolución contra un sistema; se trata de un levantamiento armado en contra de don Antonio López de Santa Anna en lo personal. Para convencerse de ello, basta releer las exposiciones de motivos que preceden al articulado en ambos planes, es decir, las consideraciones que ofrecieron los rebeldes para justificarse ante los ojos del país. Todas las razones esgrimidas tienen por objeto censurar la conducta personal del presidente. Su permanencia en el poder, se dice, es un amago para las libertades públicas y para la independencia nacional; ha vendido una parte del territorio de la república; ha hollado las garantías individuales; ha esclavizado a los mexicanos, al investirse de un poder despótico y absoluto; su administración ha consistido en la opresión del pueblo y en el enriquecimiento de los favoritos; contrariando promesas, ha perseguido a sus enemigos personales y por último, conspira apremiado por el partido conservador, para establecer una monarquía en México, insinuándose que el dictador prepara su propia exaltación al solio, con la creación de órdenes, de tratamientos y de privilegios opuestos a la igualdad republicana. En suma, que la existencia política y el destino de la nación dependen de la voluntad caprichosa de ese hombre, y que semejante estado de cosas no puede continuar. La revolución de Ayutla se ofrece, pues, a juzgar por los documentos que le dieron origen y no por las consecuencias posteriores, como un movimiento dirigido en contra del poder de un hombre que se había apropiado la cosa pública, y ésta es la circunstancia singular que nos causó aquel asombro cuando con ingenuidad nos acercamos a los textos, poniendo entre paréntesis su interpretación canonizada.

He aquí, pues, la sustancia de nuestro análisis: una revolución se lanza como un movimiento armado en contra de un hombre que gobierna despóticamente y que medita consolidar su posición con el establecimiento de una monarquía. Pero esa revolución, vagamente adscrita a un programa liberal, abre, a su vez, la posibilidad de la creación de un poder dictatorial y omnímodo dentro de la estructura jurídica de la nación. Se prepa- 
raba así el camino equívoco y oportunista de las llamadas facultades extraordinarias del poder ejecutivo.

Ahora bien, ¿qué explicación histórica profunda podemos encontrarle a esa paradoja? La vida política de Santa Anna es, sin duda, la de un hombre ambicioso y sin escrúpulos que siempre consideró el poder público como un bien susceptible de ingresar en su patrimonio personal. Es cierto, también, que poseía una de esas personalidades que por el brillo de sus extravagancias y de su fanfarronería no dejan de seducir al pueblo. Pero esas circunstancias por sí solas explican mal sus éxitos. Lo que importa ver, en efecto, es que las repetidas y rápidas ascensiones de Santa Anna no le vienen, ni de un extraordinario talento, que no lo tenía, ni de alguna sobresaliente virtud, que tampoco ninguna lo adornaba, sino de un hecho que sólo la ceguera no podría ver y que reclama nuestra cuidadosa atención, a saber: el hecho de que conociendo todo el mundo las veleidades y malas artes del personaje, el poder se lo ofrecían y él simplemente lo tomaba. He ahí, pues, la cuestión, porque ¿cuál, entonces, es el oscuro y enérgico resorte que obligaba a proceder así a quienes así, en efecto procedieron?

Esta consideración nos remite de inmediato al terreno más profundo donde se puede aprehender el sentido histórico de la revolución de Ayutla. En efecto, podemos comprender que ese movimiento fue, en el fondo, un golpe dirigido contra algo mucho más poderoso, mucho más sutil y permanente, más enraizado en la conciencia mexicana de la época que no la simple atracción de la simpatía hacia un militar jactancioso y despilfarrador. En Ayutla se desencade- nó una ofensiva contra Santa Anna, eso es cierto; pero más profundamente, contra la razón bistórica que habia becho posible el fenómeno del santannismo en el escenario de la vida mexicana. Mas si esto es así, se nos avisa también que, junto a esa razón histórica, hay otra que le es contraria: la que animó a la acción política de los hombres de ideas liberales y que, a su vez, hizo posible, frente a la solución personalista la existencia de las instituciones democráticas. En Ayutla, por lo visto, se conjuran esas dos posibilidades, esas dos razones históricas, al abrirle la puerta a la solución de un dictador reformista. ¿No será, entonces, que nos asomamos al momento inicial de una síntesis? Mas ¿en qué consisten exactamente esas dos tendencias que así se entrecruzan? ¿A qué sentimientos arraigados podremos referirlas? Tal la interrogación a que nos ha conducido nuestro estudio y que solamente podrá contestarse si dirigimos la mirada hacia los sucesos anteriores. Así, nos parece, se revelará el sentido histórico de la revolución que conmemoramos; pero esa tarea pide consideración aparte.

\section{Ilustración, tradicionalismo $y$ democracia}

La investigación suscitada en el apartado anterior nos remite por lo pronto, puesto que es el principio obvio de nuestra historia nacional, a la revolución criolla de 1810, es decir, a la insurgencia. En el desarrollo final de la ideología que inspiró a ese movimiento, vamos a encontrar la primera expresión de una de esas dos razones históricas a que hemos aludido, la expresión política, en efecto, de la tendencia liberal democrática que 
combatió a la otra, la de las soluciones personalistas. Ésta, a su vez, aparece ya muy claramente perfilada desde el principio del movimiento de independencia iniciado y realizado por Agustín de Iturbide. Precisa, pues, distinguir bien el matiz diferencial de esos dos grandes sucesos, porque en la pulcra comprensión de las vertientes que representan está la clave del problema que nos ocupa y quizá, una más penetrante visión del acontecer mexicano a partir de entonces. Fijemos la atención, por lo tanto, en el fondo histórico de esos dos hechos inaugurales de nuestra historia nacional, como base indispensable de esta investigación.

Considerado como un proceso ideológico, la rebelión insurgente es un movimiento de reforma político-social que se desprende de un horizonte abigarrado, mezcla ecléctica de postulados de la Ilustración, de pasiones y anhelos románticos y de tradicionalismo católico. Pretender explicar la insurgencia como un brote puro del enciclopedismo del siglo XVIII es cómodo, es habitual; pero es deformador por exceso de simplificación. Notemos, desde luego, que los insurgentes nunca abandonaron su fe heredada, y si cabe, quizá, la sospecha que en algunos de ellos ya no tenía los quilates de sumisión que requiere esa actitud espiritual, lo cierto es que no encontramos nunca en el programa insurgente esa animosidad abierta y feroz contra la religiosidad y visión cristianas que fue el resorte más visible y poderoso del movimiento ilustrado. Por lo contrario, la insurgencia se presentó como una cruzada en favor de la fe católica; como un movimiento querido por Dios y apadrinado por la Guadalupana, y por eso nada irritó tanto a sus caudillos como la acusación de herejía y de ateísmo con que quiso desprestigiarlos la propaganda realista. Ellos, a su vez se defendieron lanzando los mismosepítetos a los gachupines, ofreciendo así un espectáculo que por sí solo habría bastado para que los filósofos del XVIII rechazaran enérgicamente la paternidad del movimiento. No se siga diciendo, pues, que los insurgentes fueron unos ideólogos de la Ilustración, lo que no impide reconocer, sin embargo, que hicieron suya, como base de acción revolucionaria, la principal preocupación de orden pragmático hacia la cual derivó esa filosofia, a saber: el anhelo de mejorar la sociedad por medio de reformas políticas y educativas, cuyo fundamento de verdad y de justicia era la creencia en una ley natural suprema deducida de la racionalidad esencial del hombre. Ese programa, claro está, llevaba implícita una teología mecanicista y determinista que, en el límite, substituía con la naturaleza al dios personal del cristianismo. Pero semejante extremo arredró a los mismos ilustrados, sobre todo a los más cercanos al romanticismo, y por eso no dejaron de hablar de la existencia de un Ser Supremo, de un Gran Arquitecto o Artífice, de un Dios moderador de los imperios y autor de la sociedad y de no sabría yo decir cuántos otros sucedáneos, más o menos inocuos del Dios padre de los cristianos. En vista de ese teísmo y situados como estaban los ideólogos y los caudillos insurgentes a gran distancia de las intimidades filosóficas de la ilustración, no se dificulta comprender que hayan podido apropiarse las consecuencias políticas y reformistas de aquella doctrina racionalista y conjugarlas, sin apremios lógicos y 


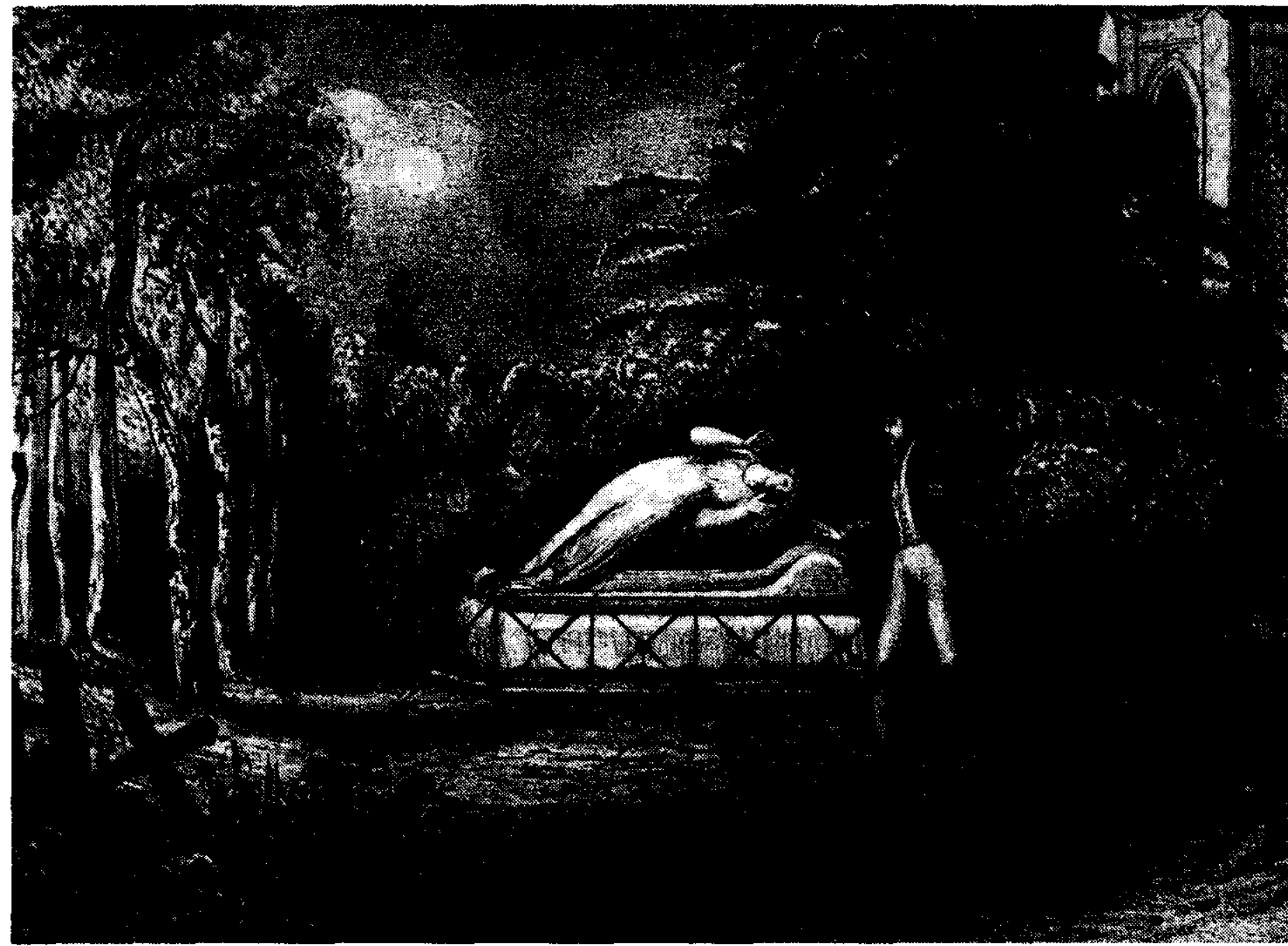

teológicos, con su fidelidad al catolicismo, tanto más, cuanto que era muy preciso exhibir esa fidelidad para no comprometer el buen suceso de la rebelión.

Esta posición ecléctica, todo lo doctrinalmente endeble que se quiera, pero que a fin de cuentas proveía a los rebeldes de un programa atractivo, progresista y humanitario, sin por eso alarmar la conciencia religiosa del pueblo, fue la que permitió lanzar la revolución hacia la meta optimista de alcanzar en breve la felicidad pública definitiva con sólo enarbolar la bandera dieciochesca del amor a la humanidad y a la verdad y del odio implacable a la tiranía y al despotismo. El eco de estas palabras altisonoras, de que tan llenas están las letras declamatorias y lloriconas de muchos grandes ilustrados, se deja es- cuchar con igual insistencia en las proclamas, manifiestos y decretos de nuestros padres los insurgentes. No sin invocar siempre al Dios de la Iglesia católica, los vemos comulgando tácita o expresamente con el dogma ilustrado, tan anticatólico, de la perfectibilidad indefinida del hombre y aceptando, con ingenuidad enternecedora, la creencia fundada en ese dogma de que bastaba remover al tirano para que un pueblo alcanzara inevitablemente las cumbres de una prosperidad sin limites y de una dicha eterna. Despojados los europeos del poder público, la vida mexicana entraría, por fin, en el orden de la bella y armoniosa secuencia de los procesos universales, que en cierto curioso sentido representan la sabiduría de la providencia divina y todo sería en adelante, paz, humanidad y dicha. 
En este breve balance de nuestra deuda a las ideas ilustradas, parece elemento discordante la revolución misma, en cuanto que fue una revolución violenta. Salvando el cristianismo, lo que más detestaron los ilustrados fue, quizá, la violencia, cuya causa, por otra parte, no dejaba de remontar a las supersticiones religiosas. Amaron la paz universal como trasunto que les parecía ser del orden cósmico y frente a los medios violentos, que proscribían, opusieron la fuerza de la razón y del buen sentido, las luces que desterrarían para siempre de la historia a las tinieblas. En este punto también conviene matizar la posición de los insurgentes. Por un lado, es preciso reconocer que en todo tiempo hicieron mérito de su pacifismo, alegando que todo intento de conciliación y convencimiento se frustraba ante la ceguera del tirano que combatían; y que si combatían con las armas era porque la guerra se les había impuesto como único camino. Sin duda tenían alguna razón: es notoria la incomprensión de las autoridades españolas respecto a los derechos y exigencias de las colonias, pero, por otro lado, es en este aspecto belicoso de la insurgencia donde empieza a borrarse el vínculo con la ilustración y a aparecer el elemento romántico que más tarde agravará con sus gesticulaciones muchos de los desastres nacionales. Y es que la guerra se encendió en Dolores con un gesto, bello si se quiere, pero justamente por la índole de su belleza muy poco enciclopédico. No cabe duda de que el Hidalgo de la tea encendida es el hombre de la pasión, la cosa de que más abominaban los ilustrados como retrato vivo de lo irracional, es decir, de lo malo; la cosa, en cambio, que más adoraban los románticos como exaltación de lo humano, es decir, de lo bueno. Este elemento pasional de la rebelión insurgente es claramente romántico cuando examinamos su contenido concreto, porque no se trata de la pasión que despertaba el espectáculo de la tiranía, ni mucho menos aún de la pasión por la fe racionalista, entusiasmos que, disfrazados por la parsimonia que imponía el buen gusto, habrían compartido un Diderot, un Gibbon y hasta Hume. Se trataba de la pasión democrática nacionalista que apelaba a los sentimientos populares y que halagaba el viejo resentimiento de la clase criolla. Frente a este hecho indudable, es lícito colocar a la insurgencia a mucha distancia del ambiente cosmopolita que tanto amaron y dígase de paso, que tanto honra a los mejores espíritus de la Enciclopedia. No se proclama en Dolores la ciudadanía mundial; se exige el reconocimiento de los derechos del criollismo para regir sus destinos particulares y para disfrutar las abundancias de esa parte del cosmos que se llamaba la Nueva España. Abolir la esclavitud; decretar la igualdad natural de todos los hombres; anhelar el progreso y creer en la posibilidad de alcanzar pronto e inevitablemente la felicidad pública, todo eso reconoce sus orígenes en la doctrina ilustrada de la ley de la naturaleza; pero el apasionado deseo de constituir una patria que, como decía Morelos, fuese gobernada democráticamente por la voluntad de las masas; de crear una nueva nación encerrada en sus fronteras, celosa de sus riquezas, orgullosa de su pasado indígena y codiciosa de su soberanía particular, ese fue el otro sueño que trajo consigo la insurgencia; su sueño patriótico y romántico, el re- 
sorte sentimental y vigoroso que la llevo a los campos de batalla.

Un programa de mejoría social fundado en la vision ilustrada y racionalista de la naturaleza y junto a él, una especie de teísmo cristiano católico y un sentimiento nacionalista democrático, he ahí, en resumen, el fondo histórico de la revolución insurgente. Este cuadro nos permitirá precisar la utopía liberal que ese movimiento lego a la historia de México como una de las dos grandes tendencias que nos ha parecido presiden su desarrollo. Pero además, también servirá para hacernos comprender a la otra, a su enemiga, porque, como veremos, se trata en última instancia de dos vertientes de un mismo impulso general.

\section{El legado dualista de la insurgencia}

Todo el bullicio de las anuales celebraciones patrias no puede, ni debe, ocultar un hecho indiscutible: que la rebelión insurgente fue un fracaso militar rotundo. Arnaiz y Freg ha subrayado el discernimiento de nuestro pueblo que, al saber exaltar el heroísmo sobre el éxito, relegó a Iturbide a un segundo plano de su gratitud respecto a Hidalgo. Pero en ese discrimen, al parecer intuitivo y sentimental, es preciso discernir, a su vez, la razón histórica que le sirve de base, a saber: el liberalismo del legado ideológico de la insurgencia. Trascendiendo el desastre bélico, allí están las ideas y los sueños que, entre precipitaciones angustiosas y presagios de derrota, dejaron consignados los insurgentes en la Constitución de Apatzingán, ese documento político cuya significa- ción ha sido tan desatendida. Los reparos jurídicos son tantos, comoson graves, como son ciertos. No menores han sido las críticas en orden a su contenido político. En efecto, el hecho de haberse erigido en ese código a la religión católica en iglesia del Estado y el de haberse admitido el sistema centralista de gobierno, han pesado tanto que muchos quieren encontrar alli el antecedente culpable del centralismo conservador y clerical de los años posteriores. No podemos acceder a esas condenaciones: los reparos jurídicos no calan hasta el espíritu que vivifica las ineptitudes técnicas, y en cuanto a lo otro, es claro que se trata de un juicio a posteriori puramente analógico que ignora, por eso, el mensaje central que quiso trasmitirse. Intentemos, pues, una comprensión más auténtica, es decir, una inteligencia histórica del célebre documento.

El decreto constitucional para la $l t-$ bertad de la América mexicana que fue sancionado por el Congreso insurgente reunido en Apatzingán el 22 de octubre de 1814 no es, como no lo es nada, un producto de generación espontánea; es, por lo contrario, el resultado final que alcanzó el proceso ideológico de la insurgencia. Por eso, si aspiramos a comprender lo uno, será necesario entender lo otro. La trayectoria, por otra parte, no es demasiado dificil de reconstruir en sus lineamientos más generales si nos atenemos a las cuestiones decisivas que van apareciendo en la serie de unos cuantos documentos señeros.

En la Proclama a la nación americana que lanzó Hidalgo en 1810; en su famoso Decreto de Guadalajara, aboliendo la esclavitud y los tributos que gravitaban sobre las castas y en el impor- 


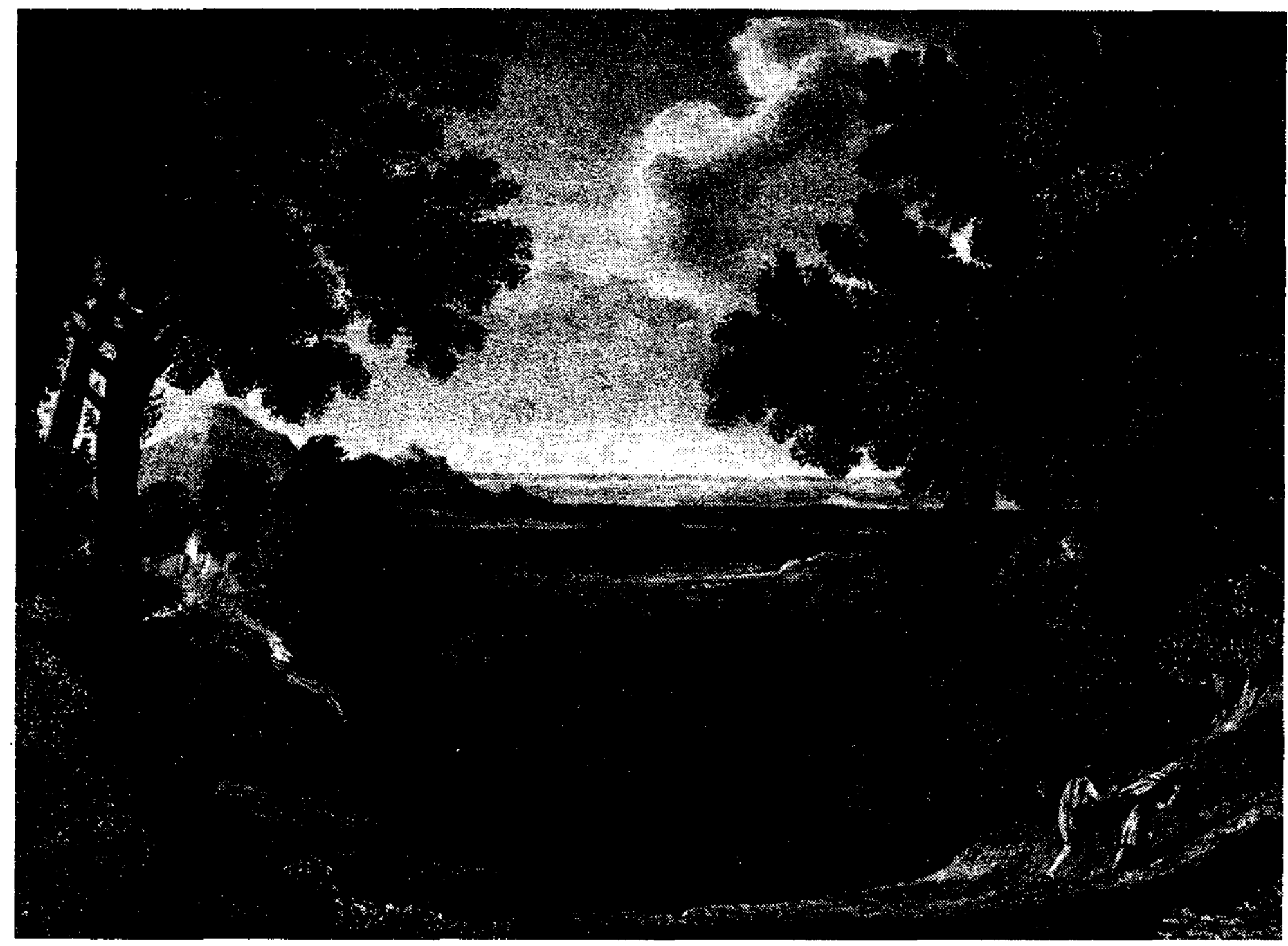

tante Manifiesto y plan de paz $y$ de guerra redactado por José María Coss en el real de Sultepec (16 de marzo de 1812), podemos percibir con suficiente claridad el programa inicial de la insurgencia. El objeto que se persigue es sencillo, es justo, es inmediatamente asequible, es el deseo de la nación entera. Se trata de desposeer a los españoles europeos, "los gachupines", del mando y del poder que ilegítimamente tienen, y que automáticamente y por un derecho imprescriptible recae en los americanos. Se pide, pues, la independencia de la América mexicana. El fundamento de esta petición es obvio: la nación entera, dicen los insurrectos, sólo quiere lo que es suyo; reclama sus derechos naturales, que son los derechos de la humanidad. Si hay guerra, es porque los europeos la han obligado; pero la guerra podría terminar en un día si los españoles comprendieran que la causa de la insurrección es también la suya, no sólo por la justicia que le asiste, sino por conveniencia personal. La insurgencia , en primer lugar, no es enemiga de la religión; es, por lo contrario, su celosa defensora; pero, en segundo lugar, si el gobierno accediera a la justísima pretensión de los americanos, las personas y propiedades de los españoles serían respetadas y todos los habitantes del reino vivirían en concordia, disfrutando de un ambiente de igualdad, de prosperidad, de dicha común y de paz cristiana.

En todo esto es fácil advertir el eco de las doctrinas racionalistas y naturalistas de la Ilustración, pero mezcladas, por la razón que ya explicamos, con el elemento tradicionalista católico. Sin em- 
bargo, debemos notar que esta postura inicial de la insurrección, que tiene por meta lógica la reforma de la sociedad mexicana, carece de un proyecto positivo para realizarla. Precisa ver, ciertamente, que hasta ese momento los insurgentes no tienen más plan de acción que apoderarse del gobierno del país; pero que no se ha pensado todavía en la necesidad de transformar el ambiente social con la implantación de un nuevo sistema. Que esto fue efectivamente así, se ve en los límites que los mismos caudillos le impusieron a la emanda de independencia. Hidalgo ınzó la revolución en nombre del rey; dea que explicita muy bien el doctor usé María Coss en su conocido Manilesto y plan de pazy de guerra de marzo e 1812. Independencia de la nación, so sí, pero con expreso y voluntario catamiento de la autoridad del trono. Sobre este pie", explica Coss, "ha camiado siempre el partido de la insurreción". Se trataba, pues, de lograr por la serza el reconocimiento de los derehos de los mexicanos a gobernar al país omo una entidad política independienz de la española, pero sería una entidad tegrante de la monarquía. Fernando II iba a ser el rey de dos distintas aciones. Se deduce con claridad, por lo into, que en esta etapa inicial del prorama insurgente, la tesis consistía en ue las condiciones propicias para alanzar la prosperidad y la dicha se btendrían con sólo remover el despousmo de los europeos españoles que venían usurpando el poder público; pero no aparece el deseo de alterar de raíz el sistema. Ahora bien, este pensamiento, pasivo por su índole general, no es sino la primera etapa de la ideología insur- gente. Examinemos su desarrollo posterior.

Un año después del Manifiesto de Coss la situación cambia radicalmente cuando el Congreso de Anáhuac proclamó, el 6 de noviembre de 1813, el Acta de la declaración de la independencia de la América septentrional. En ese documento se afirma, no ya que México aspira a gobernarse bajo el cetro del rey español, sino que, por haber recobrado el ejercicio de su soberanía, rompe todo vínculo con el trono. Respecto a cuál sería el futuro sistema de gobierno nada se dice, salvo que el Estado sería católico, apostólico y romano; que no toleraría el uso privado de ninguna otra religión y que protegería a la Iglesia y velaría sobre la pureza de la fe y de sus dogmas. En el Manifiesto que acompañó al Acta, el Congreso explica los motivos de su trascendental decisión. México, se dice, venía sufriendo el yugo de una dominación extranjera, cruel y despótica; a los mexicanos se les han conculcado los derechos de todos los hombres y negado hasta el sentimiento de la felicidad; el rey fue para el americano un poder inaccesible e infalible; los habitantes de la Nueva España no conocen sino el hábito de la tiranía y de la obediencia ciega; la sociedad padece del cáncer de los monopolios y de los privilegios, y las industrias, las artes y el comercio languidecen en un atraso espantoso. Con motivo de los sucesos políticos en la península, sobrevinieron ciertas circunstancias que hicieron concebir la esperanza de una mejoría, pero pronto se vio que no hay posibilidad de entenderse con los tiranos. La guerra, sigue explicando el Congreso, fue inevitable, aunque todavía se mantuvo la 
fidelidad al trono. Ahora, sin embargo, se ha visto la inconsecuencia de esa condición y los americanos no se han arredrado ante la gloriosa tarea de recobrar el ejercicio de su soberanía: México declara, pues, su independencia absoluta. El primer paso consiste en el exterminio de los tiranos; pero eso no es todo: es preciso poner en obra la regeneración social cuya perfección ya se promete y se vislumbra. La instalación y funcionamiento de un Congreso nacional es la garantía de ese hecho. El Congreso, se añade, fijará su atención preferente en organizar el ramo ejecutivo.

Bien advertimos el cambio que se ha operado: en lugar de la idea inicial de sólo remediar el despotismo sin alterar el sistema, ahora tenemos la idea de alterar el sistema para que no haya despotismo. A esto se debe la declaración, de otro modo tan extemporánea, de que el Congreso se ocupará en primer lugar de la organización del ejecutivo. Pero es de advertirse, además, que esa promesa anuncia ya de un modo inequívoco que, como diría Gibbon, el Congreso ya respiraba "el aire puro y vigoroso de la república ${ }^{n}$. Con estas decisiones, la ideología insurgente entra en la fase positiva de su desarrollo lógico: su programa de reforma social deja de conformarse con la idea de alcanzar la felicidad pública con la sola remoción del obstáculo de la tiranía; ahora se trata de procurarla mediante la implantación de nuevas instituciones.

A la distancia en que estamos colocados, es dificil honrar el valor que fue necesario para imponerle a la revolución ese sesgo que la hizo derivar hacia el republicanismo, tanto más, cuanto que en opinión de una inmensa mayoría del país, ese sistema se asociaba con el desorden de las costumbres y con el ateísmo. Por eso, sin duda, el Congreso palparía la necesidad de incluir en el Acta de Independencia aquellas profesiones de dogmatismoe intolerancia religiosos que hemos visto y que equivalían poco menos a la promesa de crear una inquisición estatal. La inconformidad de José Ignacio Rayón a que se hiciera la declaración de independencia absoluta, nos muestra muy a lo vivo el peligro que se corría al adoptarse tan osada decisión. Rayón está de acuerdo con la idea, pero no le parece oportuno exteriorizarla. La fidelidad al rey, dice, ha sido la más fuerte bandera de la insurgencia; cuando en alguna ocasión se ha expresado lo contrario, las filas de los rebeldes experimentan deserciones considerables. Si se hace pública la pretensión de ir más allá de la mera reforma del poder arbitrario, se amenaza el éxito militar de la causa, y no habrá modo de mantener el orden y la sumisión de los indios. El Congreso, sin embargo, se creyó en el deber de desatender esas precauciones y cumpliendo con su promesa dio forma a las nuevas ideas al promulgar al año siguiente la Constitución de Apatzingán.

Las anteriores consideraciones nos ponen en estado de reducir el análisis del documento de Apatzingán a los límites precisos pedidos por nuestro actual propósito. Pues bien, en la breve exposición preliminar, el Congreso manifiesta que, como representante de la voluntad nacional, sustrae a la América mexicana de la dominación extranjera y declara, ya sin ambages, que sustituye el despotismo monárquico con un sistema de gobierno, "que reintegrando a la nación en el goce de sus augustos im- 
prescriptibles derechos, la conduzca a la gloria de la independencia y afiance sólidamente la prosperidad de los ciudadanos". Ese sistema que no es sino el republicano, está cimentado, se nos dice, en unos principios sencillos y luminosos que son la esencia de toda constitución política que sea justa y saludable. Se trata, claro está, de esos principios constantes y universales que los filósofos ilustrados creyeron discernir como esencia de lo humano y cuya consagración en un código político bastaba para garantizar su bondad, puesto que lo armonizaba con el orden perenne y racional del universo, es decir, con los poderes infinitos de la naturaleza. Eran, pues, aquellos mismos principios que, por la supuesta evidencia con que se manifestaban en todos los corazones no corrompidos por la superstición y por la tiranía, hicieron creer que la labor de constituir a una nación sería "obra de un día", según se llegó a decir en la Asamblea Nacional de Francia.

Pese a toda esta carga de fe y optimismo ilustrados, la Constitución de Apatzingán, fiel al eclecticismo de sus autores, empieza por reconocer que la religión católica será la única oficial, si bien nada se dijo en orden a proscribir el ejercicio de otras religiones como asunto privado. Este fue un paso importante, el primero en la lucha por la tolerancia liberal en materia de creencias religiosas. Por lo demás, no hace falta entrar aquí en demasiados detalles respecto al contenido de la Constitución. Encontramos consignadas muchas de las garantías individuales que ha admitido nuestro derecho público y vemos aparecer el embrión de nuestras instituciones democráticas: la soberanía radica en el pueblo; su ejercicio corresponde a una asamblea de representación popular; se establece el derecho del sufragio; la ley es igual para todos; es la expresión de la voluntad general y constituye la norma racional de la conducta en las relaciones sociales; se establece la división clásica de tres poderes, los cuales no podrán ejercerse por una sola persona, ni por una sola corporación. Se declara que el gobierno no se instituye en beneficio de una familia, de un hombre o de una clase. El ejecutivo queda depositado en tres personas con igual autoridad, que cambian por un sistema de renovación anual. Sus facultades están cuidadosamente limitadas y se ponen trabas para impedir que alguno de sus miembros pueda llegar a ejercer un poder dictatorial. En un artículo expreso los legisladores creyeron necesarioestablecer como dogma de fe política que "es contraria a la razón la idea de un hombre nacido legislador o magistrado".

Ahora bien, de este resumen se destacan dos consideraciones esenciales: por una parte, tenemos la fe y la confianza en alcanzar la felicidad pública por medio de la implantación de un nuevo sistema legal democrático; por otra parte, la obvia desconfianza respecto a los hombres depositarios del poder. El ideario insurgente ha dado una vuelta completa, supuesto que en su primera etapa se acepta como evidente la idea de un magistrado por nacimiento, el rey de España, y se pretende lograr la prosperidad y la dicha sin alterar el sistema existente. Pero lo decisivo en este cambio realizado en la Constitución de Apatzingán, es que en ella cobra cuerpo como realidad mexicana el gran utopismo de la Ilustración que no fue, como sabe- 
mos, sino la creencia de poder alcanzar en este mundo, por medios puramente humanos asequibles a la razón, un estado de concordia, de prosperidad y de dicha común. En Apatzingán nace pues, para nosotros, la tendencia, tan patente en nuestro fervor legislativo, de ver en la norma constitucional un poder mágico para el remedio de todos los males, porque en el fondo de esa creencia está la vieja fe dieciochesca, de que la ley buena no es sino trasunto de los secretos poderes del universo. El hombre, se pensaba, es sobre todo el producto de su ambiente social; reformar ese ambiente de acuerdo con la armoniosa sabiduría de la naturaleza, es tanto como regenerar al hombre y ponerlo en el camino de su felicidad. ¿Cómo, entonces, actualizar este sencillo y sublime silogismo? La respuesta era obvia: imponer a la sociedad una ley que consagrara los principios del evangelio de la Naturaleza y todo lo demás se dará por añadidura, puesto que el hombre es en sí, bueno y perfectible. Este fue el sueño de los hombres de Apatzingán; es el legado, tan rico en consecuencias, que nos trasmitió la insurgencia.

Dos utopismos: Apatzingán e Iguala

Aquí es preciso abrir consideración separada, porque en este punto apresaremos, por fin, el origen de las dos tendencias opuestas que provocaron la gran disidencia de nuestra historia nacional y que nos pareció se conjugaban en Ayutla.

En efecto, el desarrollo de la ideología insurgente, lo acabamos de ver, logró elevar al plano de la conciencia nacional la convicción de que se alcanzaría la prosperidad y grandeza del país mediante el arbitrio cuasi mágico de la ley. Una constitución política sabia y buena operaría el deseado milagro, creencia tan arraigada entre nosotros que apenas ahora empieza a encontrar sus límites justos. Mas esta tesis, esta fe, dejaba como problema concreto la determinación del grado de personalismo que debería admitirse como elemento en el sistema político redentor, porque, en última instancia, se trataba de un gobierno de aplicación humana. Muy bien eso de modificar favorablemente las circunstancias sociales mediante instituciones racionales fundadas en los principios evidentes inscritos en la naturaleza por el Ser Supremo; esa era la fórmula mágica incontrovertible. Sin embargo, como no sería el Ser Supremo el encargado de aplicarla, sino que la tarea tenía que confiarse a unos hombres, se suscitó la gran cuestión del alcance de las facultades que deberían concederse a los gobernantes, sobre todo, al primer magistrado ejecutivo, cualquiera que fuera su denominación. Por más vueltas que se dieran, siempre aparecería el elemento contingente de la personalidad individual, el escollo irreductible en el gran debate histórico entre Hobbes y Locke.

La solución que los filósofos ilustrados encontraron a ese problema, fue la resultante de una lógica contradicción entre su optimismo y su desconfianza. El ideal teórico era la no intervención gubernamental, es decir, el mínimo de facultades ejecutivas, ya que creerían en la espontánea perfectibilidad del hombre, en su innata bondad y en la idea de que sus actividades económicas eran de suyo 
y naturalmente benéficas para la sociedad. Sin embargo, como ese ideal encerraba la obvia paradoja de la desconfianza en la innata bondad que también era forzoso suponer en los gobernantes, puesto que participaba en la esencia humana, hubo de llegarse a la idea del despotismo ilustrado, es decir, a la aceptación de un magistrado poco menos que omnipotente, pero benévolo y sabio que vigilara y acelerara la marcha hacia la prosperidad común; un magistrado que, como dijo de sí mismo Federico el Grande, fuese "el primer servidor del Estado". El déspota ilustrado no era, pues, ni el monarca providencial del derecho divino de los reyes, ni el magistrado popular del derecho democrático de las masas; era una combinación de ambos, algo así como el vicario del Gran Arquitecto del universo. Pero esa fue la solución clásica de la filosofía política de la ilustración y puesto que era eso, no podía ser la solución entre nosotros, vistas las exigencias poderosas de los elementos heterogéneos que se mezclaban en el programa mexicano. Ya notamos antes que la inspiración de cepa ilustrada que impulsó a la insurgencia hacia el anhelo de reformar la sociedad novohispana, aparece combinada con la fe en la religión tradicional y contagiada por un moderno romanticismo democrático, elementos que rechazaba el espíritu puro de la Enciclopedia. Fue así, entonces, cómo ante el problema concreto de la manera de aplicar la fórmula redentora, incidieron esas dos opuestas contenciones con respuestas contrarias. Me parece, pues, que en el predominio alternante y polémico de esas dos exigencias en orden al modo de realizar el programa constitucional planteado por la lucha de la insurgencia, es donde se encuentra la explicación que buscamos para comprender el sentido histórico de la revolución de Ayutla. Veamos cómo esto es así.

El primer desenlace de la pugna está en favor del elemento democrático, cuya resolución es de escepticismo respecto al gobernante: un mínimo de facultades del ejecutivo, con una serie complicada de trabas legales para evitar la concentración del poder en sus manos y un máximo de poder en la representación popular. He ahí la respuesta. Tal, en efecto, es la solución que encontramos consagrada en el Código de Apatzingán. Ya lo vimos: el ejecutivo se deposita en tres personas, no en una; triunvirato que se renueva automáticamente cada año y cuya autoridad está celosamente limitada y responsabilizada ante el pueblo. La declaración expresa de que el gobierno no se instituye en beneficio de una clase, de una familia o de una persona y la profesión dogmática de que es irracional "la idea de un hombre nacido legislador o magistrado", no dejan duda respecto al espíritu que animó al legislador. En el documento de Apatzingán tenemos, pues, no solamente la expresión del sueño utópico de alcanzar la felicidad pública por medio de la magia de un nuevo sistema de gobierno, sino que representa, además, la solución al problema del poder pedida por el elemento democrático que venía mezclado en ese sueño. Su nota distintiva es la desconfianza en el individuo y su forma más natural es la republicana. En esta primera tentativa de la respuesta democrática se trata de admitir y conciliar las exigencias del tradicionalismo religioso, puesto que la fe católica queda 
erigida en religión del Estado. Por otra parte, la república que se pensó era centralista porque no se podía llegar de un solo golpe al federalismo, es decir, a la meta lógica del postulado que pide un mínimo de concentración de poder. Pero el desarrollo posterior muestra esas incompatibilidades y el esfuerzo por corregirlas. Tenemos, pues, ya claramente definida y presente en el escenario de nuestra historia la primera tendencia por cuyo origen venimos preguntando.

Con cuanto llevamos expuesto, no será dificil encontrar ahora el origen de la otra tendencia que se manifestará con caracteres opuestos a la primera y que responden al elemento tradicionalista que, según hemos dicho repetidamente, coexiste con el moderno democrático. Esta otra y segunda posibilidad en la actualización del programa de mejoría social, aparece claramente perfilada en el movimiento de independencia realizado por Iturbide. Creo que debe admitirse que el programa del golpe iturbidista llevaba inscrito el mismo anhelo fundamental que animó a la insurgencia: independizar a la nación; abolir el poder despótico y por medio de un sistema de administración pública que reconociera la verdad católica y que se apoyara en los principios sencillos y luminosos de los derechos de la humanidad, encaminara al país hacia su grandeza histórica. Pero la diferencia decisiva del movimiento de 1821, es que impera la razón tradicionalista sobre la democracia; es decir, que en el movimiento encabezado por Iturbide se empieza a actualizar la otra posibilidad que había en la solución de la manera de realizar el sueño redentor de la patria. En oposición al camino adoptado en Apatzingán, ahora se per- fila la idea de un poder ejecutivo omnímodo con un mínimo de trabas legales. La nota decisiva, pues, consiste en la confianza y exaltación de un hombre excepcional por sus virtudes y patriotismo. Pero no es la solución clásica del déspota ilustrado, porque se trata de un magistrado popular que gobernaría con el concurso de una representación nacional. Es decir, que así como en la primera solución se admitieron las exigencias del elemento tradicionalista, ahora, a su vez, se le concedía un lugar al elemento moderno democrático. Era lógico, por otra parte, que esta segunda respuesta encontrara su forma más natural en la monarquía, como lógico fue que la otra derivara hacia la república. En este momento inicial en que va a desencadenarse el violento diálogo de nuestra historia, tenemos, pues, frente a frente, como primera encarnación de las dos tendencias vivas que dejó la lucha insurgente, los proyectos de una república centralista teocrática y de una monarquía templada democrática, pues no otra cosa son, por una parte, el Código de Apatzingán y por la otra, el Plan de Iguala y los Tratados de Córdoba. El examen más sumario de estos documentos iturbidistas no dejan lugar a duda. Vuelve a sonar el proyecto monárquico de la primera etapa insurgente; pero con esta gran diferencia: que si se llamaba a Fernando VII o a los de su dinastía, no era ya por principio de fidelidad al trono, sino "para hallarnos con un monarca ya hecho y precaver los atentados funestos de la ambición" (Plan de Iguala, art. 4). Se trata, pues, de un trono mexicano; no ya del trono español y en principio quedaba abierta la posibilidad de que lo escalara, como aconteció, un ciudadano 
del nuevo Estado. Por lo demás, como es bien sabido, el espíritu del proyecto es fuertemente de concentración personalista del poder, bien que admitiendo el principio de unas cortes representativas de la nación que serían las encargadas de estructurar el imperio. Tanto en los articulados del Plan de Iguala y de los Tratados de Córdoba, como en el texto de las exposiciones de motivos y de las Actas preparatorias, se percibe el eco de las doctrinas naturalistas enciclopédicas, tocante a los imprescriptibles derechos del hombre y a la posibilidad efectiva y rápida de alcanzar el bien social. Encontramos el mismo lenguaje altisonante y sentimental empleado por los hombres de Apatzingán; pero ahora, aparece también la arrolladora tentación de exaltar a un hombre por encima de los demás, en el caso concreto, a Iturbide. Pero es que, y esto es lo decisivo, ese hombre se of rece a la vista de todos como el salvador de la patria, el redentor, el hombre indispensable y providencial; sentimiento, indudablemente popular, donde cobra realidad en el campo político con un vigor extraordinario el tradicionalismo católico que alimenta toda esta nueva situación. La tesis teológica de la redención del mundo por un Hombre-Dios providencialmente previsto y enviado, encuentra su traducción en la tesis política de la redención de la patria por un hombre-héroe, también ordenado por la Providencia.

He aquí, pues, que ya tenemos a la otra gran razón de nuestra historia que disputará la presidencia del acontecer nacional; y así como el proyecto de Apatzingán se desarrollará lógicamente por nuestros empeños federalistas, contrarios a la intervención clerical y de raíces liberales y democráticas; así el proyecto de Iguala y Córdoba, por el despliegue del sentimiento providencialista que lo anima, explicará la exaltación de Iturbide; el centralismo conservador y clerical; los éxitos desconcertantes de Santa Anna y el sueño monárquico que, con ofrecerse tan fantástico, no pudo desterrar ni la esclarecida mente de un Lucas Alamán.

En el fondo de las dos soluciones que hemos distinguido como las posibilidades históricas, es decir, efectivas que legó la insurgencia, está el terreno común del viejo programa optimista de la ilustración; pero en un caso se le sueña por la vertiente de un utopismo democrático liberal, mientras que en el otro caso, por la de una utopía personalista. El primero está alimentado por una fe romántica en un determinismo progresista; el segundo por la fe tradicional de la visión católica. Es curioso: por uno de esos vuelcos de la dialéctica de los sueños humanos, el elemento romántico democrático que es fe en el hombre, acabó en la solución de la desconfianza en el hombre; y el elemento religioso tradicional, que es recelo en la flaqueza humana, acabó por confiar en ella. En el primer caso, el gobernante se concibió como vicario de los poderes no intervencionistas de la teología racional del universo; en el segundo, encarnaba la intervención redentora y enérgica de la voluntad providencial. Ambas tesis son razones históricas que es inútil tratar de explicar o de desvanecer con declamaciones acerca de la maldad, la ambición o el ateísmo de un hombre o de una camarilla, porque si en ambos lados ha habido eso, también militan en ellos la bondad, el sacrificio y la inteligencia. Pero sobre todo, ninguna 


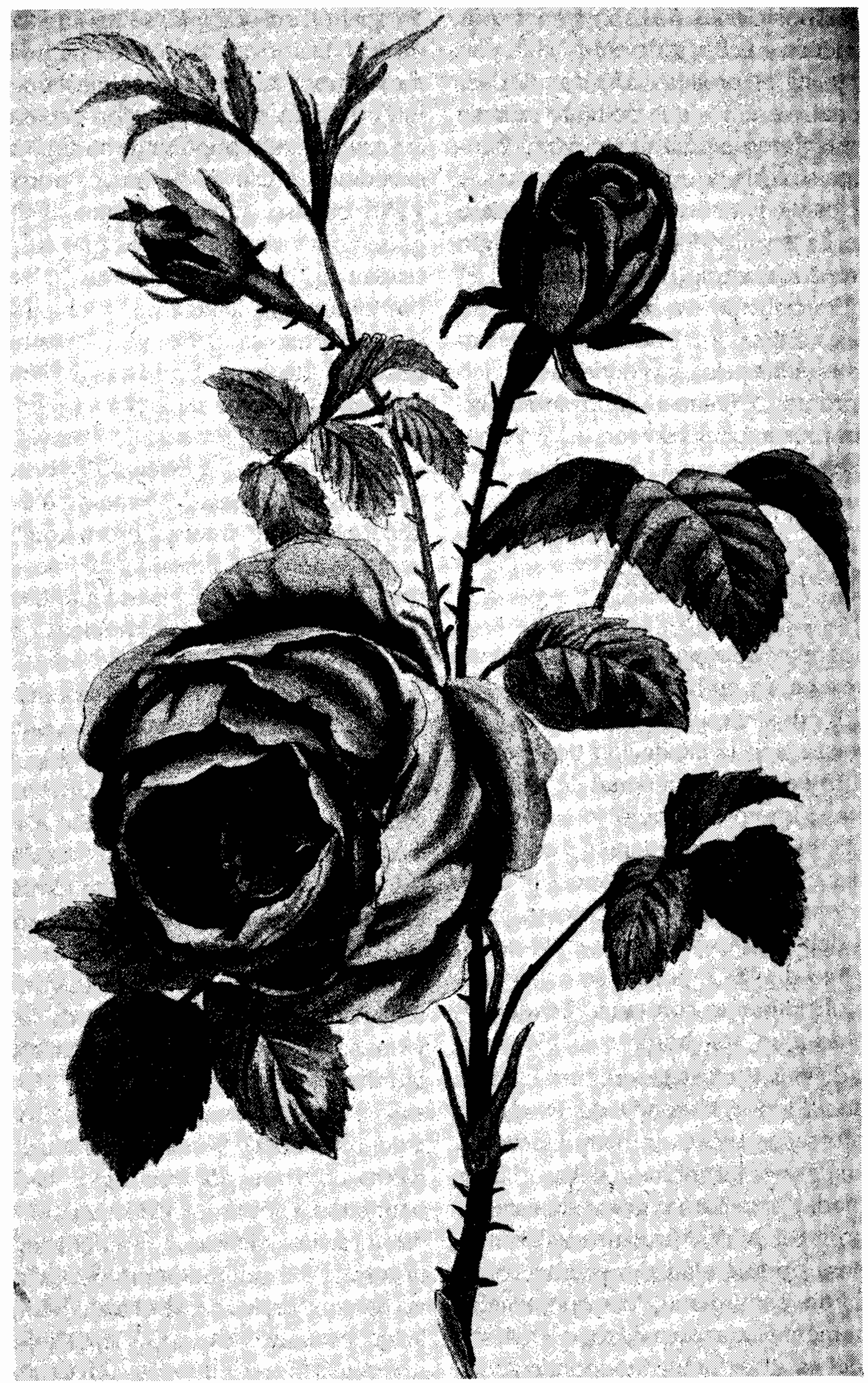


de esas posiciones nos son ajenas: nos pertenecen en el pasado entrañable y su diálogo es el proceso forjador del ser nacional. Veremos que de tanto odiarse se contagiaron mutuamente para alcanzar una síntesis de sus virtudes y de sus defectos y cuya corrección y pulimento no se ha terminado aún. Ese contagio ocurre en el campo liberal cuando el providencialismo va a convertirse en presidencialismo; es el momento de Ayutla y en ello estriba su sentido histórico más profundo. En un último apartado intentaremos explicitarlo con la brevedad que sea posible.

\section{Las tentativas de realización: el imperio y la república}

Hemos relatadoel primer acto del drama: se presentan y definen en nuestra historia los dos destinos mexicanos en proyecto. Con la exaltación de Agustín de Iturbide al trono imperial de México, triunfa primero el utopismo providencialista. El documento capital para aprehender el sentido de esos sucesos es el acta de la memorable sesión extraordinaria del Congreso Constituyente de 19 de mayo de 1822 . Nunca se ha expresado oficialmente con tanta claridad la idea de que un hombre había sido enviado por Dios para redimir al país y conducirlo por la senda de la gloria. Cuanto se ha dicho de maquinaciones inspiradas por la ambición del caudillo y calculadas para dar un golpe de Estado, no borra el hecho fundamental de su inmensa popularidad alimentada por el profundo sentimiento de que estaba divinamente llamado para regir los destinos del país que había independizado y de que, en su persona, se reanudaba la misión histórica de los emperadores mexicanos, $\tan$ brusca e injustamente interrumpida por la agresión española. Sin esa accesión popular no se explica lo sucedido en ese 19 de mayo, por más servil que se quiera suponer al Congreso; por más comprados que se pretendan los entusiasmos de las galerías. Los diputados halagaron y el pueblo aplaudio; eso es cierto; pero esos halagos y aplausos trascendian la persona y saludaban al otro mexicano como un suceso en el orden cósmico previsto y sonreído por Dios. Entreel espesobosque de adjetivos exagerados y melosos de un debate en que intervinieron hombres como Valentín Gómez Farías, se desprende una idea clara: la independencia de México estaba en la naturaleza de las cosas; México recobra el ejercicio usurpado de su soberanía; el sistema de gobierno que histórica y lógicamente le conviene a México es el monárquico; un hombre excepcional por su patriotismo y méritos ocupará el trono; este magistrado indispensable gobernará según los principios y derechos de la humanidad, es decir, sin despotismo y de acuerdo con una representación nacional; ese hombre de excepción, ese magistrado indispensable es Agustín de Iturbide, "el virtuoso, el valiente, el caritativo, el humilde, el $\sin$ igual hombre de los siglos, que el Dios de la bondad destinó para romper al águila las cadenas de hierro con que por tres siglos le hizo batir sus alas el tirano de la Españan; es "el héroe del Anáhuac" a quien, ceñirle la corona del antiguo imperio mexicano no es sino "darle lo que el cielo benigno le ha destinado"; es, en suma, el hombre divinamente prometido, largamente 
esperado, providencialmente enviado. Está claro, pues, que en esta primera tentativa de organizar a la nación predomina la tendencia personalista y providente; pero, ya lo notamos, fue preciso admitir la exigencia del utopismo democrático que venía mezclada con ella y que era su enemiga, pues, ¿no, acaso, se había declarado expresamente en Apatzingán la irracionalidad de la idea de un hombre nacido magistrado? Aconteció lo inevitable: el Congreso, es decir, el elemento popular le estorba al hombre de la Providencia; se estorbarán siempre en lo sucesivo. La pugna sobreviene y sobreviene el atropello. Pronto se deja ór en Veracruz la voz rebelde de Santa Anna, el envidioso de Iturbide y futuro candidato a la indispensabilidad. El emperador, según reza una comunicación ministerial, "abandona a su augusta esposa en la época más delicada del suceso, olvida los halagos de sus tiernos hijos, prescinde de las comodidades de su palacion y sale a combatir al disidente. Todo es inútil; ahora le toca el turno al utopismo contrario: el Plan de Veracruz (6 de diciembre de 1822) también firmado por Guadalupe Victoria, es una declaración político-dogmática contra el personalismo y en pro de la democracia. La administración iturbidista se presenta como continuidad del despotismo virreinal; la independencia se ha consumado, es cierto, pero ahora se inicia la lucha por la libertad. Cuando ésta triunfe, para lo cual, naturalmente, se está en la imposible obligación fisiológica de derramar hasta la última gota de sangre, todo se confiará en manos de un Congreso verdaderamente libre que, mediante la aplicación de la fórmula mágica de un sistema legal que de veras respete los derechos de la humanidad, conduzca al país, ahora sí, a la prosperidad y a la dicha que la Naturaleza le tiene reservadas.

El fracaso del imperio hace germinar a la semilla de Apatzingán. Se adopta, no sólo la república, sino la república federal. Era el desarrollo lógico del principio de la desconfianza que pedía un mínimo de concentración de poder; era, también, ceder a la tentación casi biológica de emular la poderosa república vecina tan desbordante de felicidad. Pero la tendencia cuyo predominio acababa de doblegarse encuentra, sin embargo, su reconocimiento oficial: el Acta Constitutiva ( 3 de febrero de 1824) y la Constitución Federal ( 5 de octubre de 1824) consagran la fe católica como religión del Estado y la nación se compromete a protegerla y a prohibir el ejercicio de cualquier otra. Pero además, se abandona la excesiva precaución de Apatzingán y en lugar de un triunvirato ejecutivo se crea un magistrado supremo, el presidente de la república, que no es en principio el hombre providencial pero que puede serlo. En esta decisión hay un primer contagio con la tendencia personalista y se abre la posibilidad legal, ya sea de un dictador demócrata, sucedáneo del hombre "nacido magistrado", ya de que algún general -tenía que ser general-escale el poder con títulos de elección divinamente deseada, o mejor dicho, por nombramiento de la jerarquía clerical, intérprete de la Providencia.

Pero por ahora México va a ensayar el gransueño democráticoliberal que desde este momento queda adscrito a la bandera federalista. Si la creación del imperio fue popular, no lo fue menos la implantación de la república. Y no hay 
paradoja, porque ambos sistemas tenían sus raíces en la conciencia nacional. $Y$ así como los debates del 19 de mayo de 1822 registran a lo vivo los sentimientos que hicieron posible la coronación de Iturbide, así en el Manifiesto del Congreso ( 4 de octubre de 1824), tenemos la expresión más elocuente del utopis'mo que trajo entre nosotros a la federación. Los legisladores conciben su obra como el final de la etapa revolucionaria iniciada en 1810. A esta etapa, pasajera por su índole misma, pertenece el imperio. Sólo la autoridad de un caudillo podía mantener el orden. La desgracia fue, sin embargo, su intento ambicioso que precipitó a la nación en el caos político; pero en medio del desorden se dejó oir la voz de la voluntad popular que clamaba por la federación de las provincias. El Congreso no ha hecho sino escucharla y darle forma legal. Se trata de un sistema que situará a México en el rango que le corresponde entre los pueblos civilizados. La Constitución consagra la igualdad ciudadana, la libertad, la paz, la justicia y la clemencia. Los poderes están equilibrados para que su concurso produzca siempre el bien y haga imposible el mal. Se limitan las facultades para evitar peligrosas concentraciones de poder.

Claro está que el sistema no es una invención del Congreso; su modelo, se nos dice, es el de la floreciente república de nuestros vecinos. Pero esto no impide que sea el adecuado: atiende a la diversidad de climas, de razas, de costumbres y de intereses, y garantiza, así, la prosperidad y el goce efectivo de los derechos de los hombres libres. Mas no sólo por eso se recomienda el sistema con la república federal, que se adaptará fácil- mente al terreno mexicano, el país se colocará de un salto audaz en igualdad con los más civilizados, anulando de un golpe trescientos años de opresión. Y como este nuevo Código reconoce los principios de la felicidad común descubiertos en el siglo de la luz y de la filosofía, nada puede evitar su éxito. ¿Nada? La verdad es que ante el Congreso se perfila el peligro tan cierto de la seducción que puede ejercer sobre el pueblo la personalidad de un hombre extraordinario; el peligro de la tendencia enemiga recién vencida. Por eso vemos que acumulan argumentos $\mathrm{y}$ halagos para conjurarlo. Allí está el trágico ejemplo de Iturbide, el "hijo ambicioso"; los mexicanos tienen como obligación primerísima la de sostener el gobierno republicano, con exclusión de todo otro régimen, léase la monarquía. El sistema republicano es el que por naturaleza le corresponde a América. Un pacto tácito pero inviolable obliga en ese sentido a todos los pueblos del continente: en el nuevo mundo impera un nuevo orden, porque estaba determinado que en él dominara necesariamente la democracia. Al peligro del providencialismo personalista se opone la certidumbre del determinismo naturalista. Pero el Congreso no ceja en su empeño de convencimiento: ¿qué ha sido la lucha de catorce años (1810-1824), sino un acumular armas para "hacer volver a las tinieblas de donde salieron a los gobiernos góticos"? ¿En qué se ha empleado útilmente esa experiencia, sino en buscar los principios de la convivencia social en las obras inmortales de quienes encontraron los derechos perdidos del género humano? Ha llegado el momento sublime de la cosecha: al abrir los mexi- 


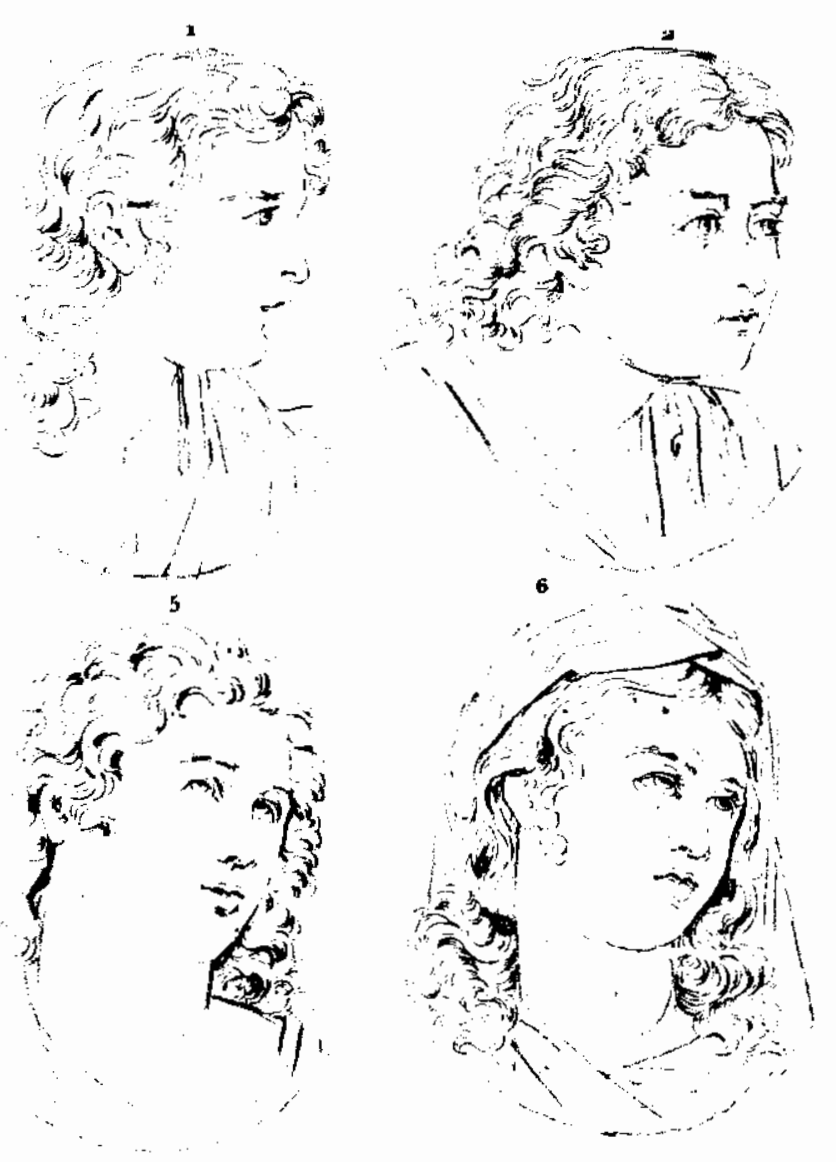

canos los ojos al torrente de luz que desprenden esos principios, "han declarado que ni la fuerza, ni las preocupaciones, ni la superstición, serán los reguladores de su gobierno". El Congreso habla en nombre del pueblo para convencerlo. Los mexicanos han dicho, dice, que después de Newton, de Rousseau, de Montesquieu y de Franklin, genios que han sabido comunicar a la obra del hombre una vida indestructible, ya no "volverán a doblar rodilla delante del despotismo y de la preocupación, siempre funestos al bienestar de las naciones". Convencidos de verdades tan patentes, los mexicanos serán patriotas, sabrán someterse a la ley, respetarán la moral y la religión; las autoridades no pretenderán abusar de sus poderes, ni salirse de sus órbitas precisas. Es necesario abandonar el hábito escolástico de los subterfugios tendientes a burlar derechos ajenos; sin estas condiciones que

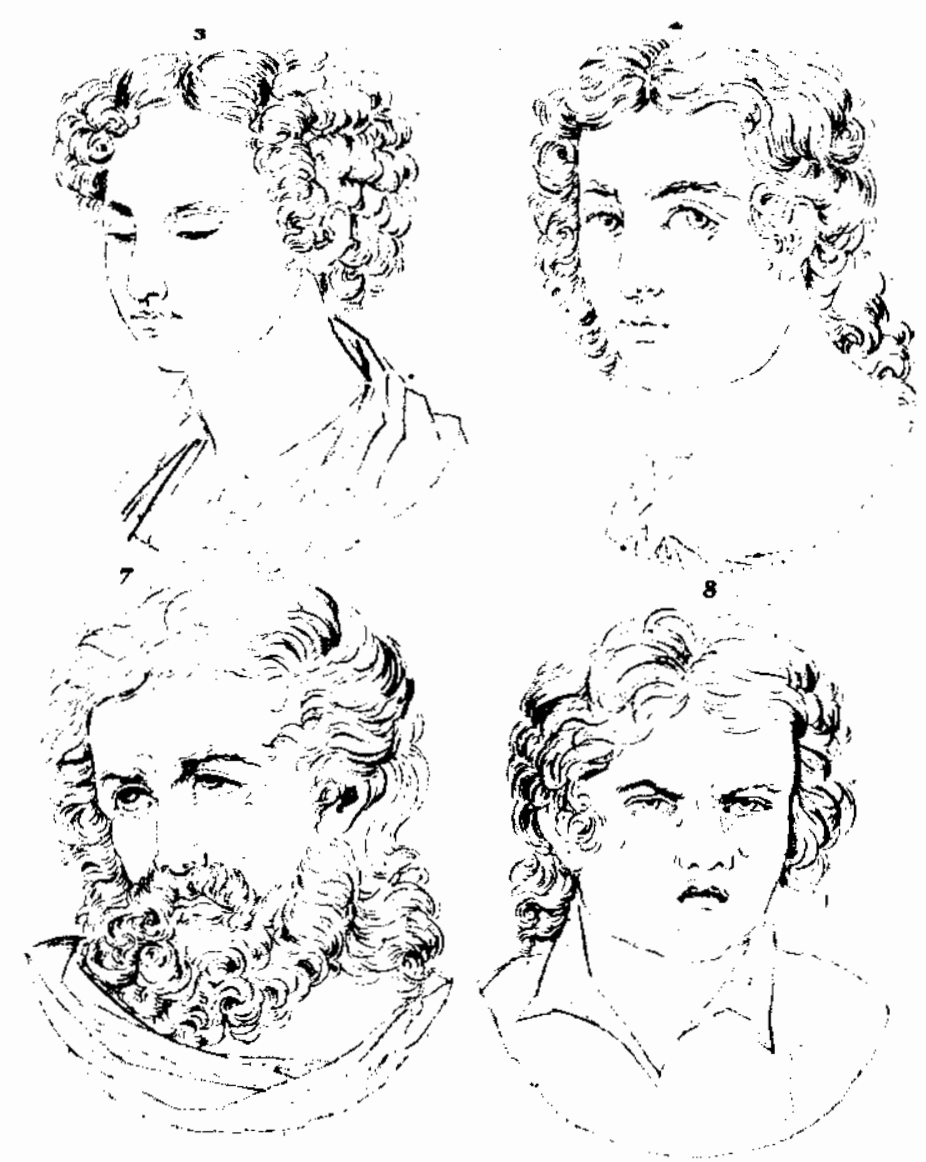

imponen la buena fe y las virtudes cívicas, México sucumbirá al capricho de un tirano, de un Marat, de un Robespierre, monstruos que proclamando los principios de la humanidad, trataron, empero, de elevarse por encima de sus conciudadanos e inundaron de sangre a la nación más ilustrada de la tierra. ¡Desconfiad de los hombres seductores! He allí el patético mensaje que, como a incauta virgen dirige el Congreso a la nación mexicana. Es como un cuento de hadas: el príncipe de la dicha está al alcance de los dedos, vedada sólo una pequeña tentación; pero el pueblo sucumbió y perdió el paraíso prometido.

En el primer imperio y en la primera federación, tenemos los intentos de realizar, respectivamente, las dos soluciones que ofrecían las circunstancias concretas mexicanas al gran proyecto común de regeneración social. En ambos casos se hacen concesiones a la ten- 
dencia contraria: el imperio admitió el principio de la representación democrática; la república se avino a la necesidad de una magistratura suprema confiada a un solo hombre. Se inicia así un proceso de síntesis que por entonces es imposible alcanzar. Los once años de vigencia de la federación constituyen un periodo en que se van perfilando como irreconciliables los programas de las dos fuerzas contrarias, es también el periodo durante el cual va surgiendo en torno a la lucha por la presidencia, el candidato al providencialismo: la figura de Santa Anna se deja sentir con creciente y amenazante vigor. Un retorno al imperio es imposible; pero dentro de la forma republicana el sistema centralista ofrecía la manera de satisfacer las exigencias de aquel viejo sentimiento. En el año de 1834 estalla el sordo conflicto. Santa Anna disuelve las cámaras del V Congreso de la Unión; se ordenan las nuevas elecciones el VI Congreso constitucional queda instalado a principios del año siguiente; unos meses después ( 5 de mayo de 1835), este cuerpo se declara constituyente y prepara el cambio de la estructura política de la nación. Se abre así el tercer gran momento en el diálogo histórico que venimos estudiando. Este tercer episodio culmina en Ayutla. Completemos, pues, el cuadro con un breve examen de los acontecimientos que nos traerán por fin a la meta de nuestro propósito.

\section{El proceso de sintesis}

En el imperio y en la federación se habían ensayado las soluciones que, respectivamente, proponían los senti- mientos del personalismo providencial y del determinismo democrático, encarnando las formas más puras que permitían la coexistencia de esas dos corrientes de la opinión nacional. Es así como aquellos dos sistemas representan, dadas las circunstancias concretas del pasado, los ideales políticos de la época. Como ideales, en efecto, van a funcionar en la compleja trama de los acontecimientos que siguieron al colapso de la primera federación. El proyecto monárquico seguirá siendo el ideal de los grupos más firmes de la reacción y por otra parte, la bandera federalista será siempre el sostén del núcleo demócrata avanzado que, con intuición certera, apellidó el pueblo de "los puros". Pero entre estos dos extremos se colocan los "moderados" de ambas contenciones, cuyo poderoso influjo viene a complicar el cuadro dualista inicial con soluciones y tentativas que varían en grados de compromiso y que, a la vez, ocasionan reacciones extremosas. Se trata, pues, de un complicado proceso de pugna y de acercamiento, de toma y daca del poder que, sin embargo, no carece de un profundo sentido de carácter positivo. Es, en efecto, el tortuoso inevitable camino que prepara la fusión de las opuestas tendencias, cuyo contagio mutuo va haciendo posible una sintesis de integración.

Considerado en su detalle el panorama de los sucesos comprendidos entre 1835 y 1854 , ofrece un espectáculo de indecible tristeza: en el seno mismo de la guerra con Estados Unidos, en que todo fue desastre para las armas mexicanas, vemos un tedioso rosario de pronunciamientos y de golpes de Estado que no 
parece mostrar sino la congénita incapacidad de nuestro pueblo para gobernarse y para establecer las bases de una convivencia civilizada. Esa, en efecto, ha sido y sigue siendo una interpretación muy aclamada como verdadera por los historiografos extranjeros y que aún hoy encuentra adeptos en el resentimiento de nuestros reaccionarios menos inteligentes. Sin embargo, si sabemos leer ese trozo de nuestra historia y con un esfuerzo de generosa comprensión nos resistimos al gusto de la fácil censura, pronto se descubre en ese cuadro de adversidades una luz que le comunica a su desorden una significación positiva en el devenir de nuestra historia, y es ésta: que en la lucha de los partidos y de los intereses, de las capillas y banderías, motivada siempre desde lejos por la paradoja interna del legado insurgente se va aprendiendo una lección decisiva, la de que era preciso integrar en una formula de síntesis a las dos tendencias enemigas, en lugar de seguir el equivoco camino de las concesiones mutuas. Se fue aprendiendo que los anhelos representados en los dos partidos eran ambos auténticos, es decir, que ambos recibían el apoyo de la voluntad nacional y que, por lo tanto, no era cuestión de concederie al contrario lo que aconsejaba el oportunismo, sino de admitirle su trozo de verdad. Se fue haciendo la experiencia de que el enemigo político más que enemigo, era el otro lado del problema, y por consiguiente, que era tan imposible que un hombre, por más excepcional que fuera, gobernara contra las aspiraciones de la reforma democrática, como que se pudieran satisfacer esas aspiraciones, sin el núcleo de cohesión mesiánica y vigorosa de una voluntad seductora. El pueblo, por decirlo de algún modo, exigía ambas cosas sin curarse de la logica de los partidos, porque el pueblo venía suspirando a igualdad de esperanzas por la llegada de su redentor político y por el advenimiento de la era de prosperidad prometida en el evangelio de las reformas liberales. Esa lección, que trajo tan profundo aunque sutil cambio al escenario histórico, encierra, pues, el sentido de aquellos negros veinte aciagos años mexicanos de la predominancia del sistema centralista, periodo que, en sucesión rápida y dramática, ensayó todas las combinaciones posibles en busca de la fórmula apetecida. La culminación de este momento, tan formativo de nuestro ser nacional, está en el Cerro de las Campanas, donde fue vencida la solución reaccionaria-liberal del segundo imperio, que cometió el error de buscar al hombre de la providencia en Austria, en lugar de encontrarlo donde estaba, en Oaxaca. Desde ese momento le queda expedito el camino a la otra formula, la liberal-reaccionaria de la dictadura porfirista que, a la vez que consolida los beneficios sociales y económicos de la reforma, le da al pueblo su presidenteemperador, prefigurado desde el emperador-presidente que debió ser Agustín de Iturbide.

La forzosa brevedad, pero también el deseo de evitar el tedio, excusan aqui el detalle tortuoso del camino que condujo a la nación a ese desenlace obligado. Pero como en él cobra su sentido el movimiento político que hoy conmemoramos, se impone recorrer ese tránsito, aunque sea a grandes pasos, hasta llegar a esa meta.

Vemos primero aparecer el centralis- 
mo de las Siete Leyes constitucionales (30 de diciembre de 1836). Este código, por sus buenas intenciones de establecer un gobierno fuerte sin despotismo y de crear un órgano (el Supremo Poder Conservador) que admitiera los progresos sociales sin suscitar la rebelión, merece nuestro reconocimiento. Es un primer intento de síntesis de las dos grandes tendencias contenciosas, pero fue realizado en una forma tan tímida $y$ estorbosa que, sin llegar a ser una integración, dejó insatisfechos a los dos partidos.

Poco antes de la promulgación del centralismo, Santa Anna, que capitalizaba hábilmente su rebeldía contra Iturbide como el acto fundador de la república, logró darle un impulso incontenible a su prestigio personal, ya muy grande, con motivo de la separación de Texas. Se perfiló en la imaginación popular como el Marte mexicano, el escudo de la patria, que reducía a la obediencia a los separatistas y que, llegado el caso, coronaría con laureles la "necesaria y gloriosa guerra" como se llegó a decir, con los Estados Unidos. El triste e injusto incidente que por entonces ocurrió con Francia, le dio la oportunidad de reparar con unas heridas la avería que padeció su prestigio en San Jacinto. Nunca se ha pagado tan caro un simple accidente del trabajo profesional: ya "benemérito de la patria", el camino hacia la "alteza serenísima" estaba asegurado. El primer paso que dio para lograr ese objetivo fue cuando, al frente de un ejército rebelde que traía a los generales Paredes y Valencia en sus filas, dictó Santa Anna en Tacubaya las famosas Bases (28 de septiembre de 1841) de ese nombre, que pusieron fin a la adminis- tración de Bustamante e inauguraron la dictadura personal. El intento de síntesis había fracasado y el péndulo gravitaba hacia el personalismo providente.

Las Bases de Tacubaya hicieron de Santa Anna el depositario de un poder ejecutivo omnímodo que no podía ser responsabilizado sino ante el Congreso constitucional que, después de organizada nuevamente la nación por el constituyente que iba a convocarse, debería quedar instalado. La dictadura de este periodo representa, ya lo indicamos, la exaltación del personalismo; pero en su seno se agitan vivas las fuerzas reformistas democráticas, de tal manera que no es sino un momento preparatorio para un nuevo ensayo sintético. Bajo la mirada misma de Santa Anna se eligió e instaló una asamblea constituyente que cobijó centralistas moderados y federalistas puros, enemigos los dos, aunque con distinto matiz del personalismo extremoso. Y como en los últimos meses del imperio, el choque entre el Congreso y el "héroe" fue inevitable y con las mismas consecuencias, Santa Anna disolvió al constituyente, sólo que sin comprometerse como lo hizo Iturbide. Una maquinación transparente, pero eficaz, logró sustituir al Congreso por una Junta de Notables, pero notables por su antirreformismo. A esa corporación se debe la segunda Constitución centralista llamada Bases de la organización política de la República mexicana que fue promulgada el 13 de junio de 1843.

Este código nada ofrece de muy notable. Contrario a los proyectos de la reforma, consignó, sin embargo, un espíritu liberal de respeto a las garantías de los individuos y de división de los poderes. Producto de una maquinación 
de Santa Anna, las tendencias democráticas eran demasiado poderosas para ser ignoradas. Se trata, por consiguiente y a pesar de todo, de un nuevo intento conciliatorio de la reacción. Pero un intento que todavía concibe la posibilidad de mantener el predominio de una fuerza a base de concesiones a la otra, no a base de una integración. Santa Anna sigue en el poder investido de las facultades que se fabricó en Tacubaya y cuando por fin se logró instalar un Congreso constitucional conforme al nuevo sistema centralista, nada pudo evitar el conflicto. Una vez más la voluntad individual del hombre encumbrado por el pueblo choca con la voluntad colectiva que representa al pueblo. Pero como Santa Anna no ve la necesidad de someterse, surge la inevitable rebelión que lo obliga al destierro.

El nuevo presidente es Herrera, cuya única preocupación es negociar de un modo decoroso con Estados Unidos el asunto de Texas. So pretexto de traición, se levanta el general Paredes en San Luis Potosí (14 de diciembre de 1845) y conforme a las bases de su rebelión se hace nombrar presidente con facultades también omnímodas. Pero Paredes no era un "héroe" ni candidato, por lo tanto, a la redentoría del país. Se trata de otra cosa muy distinta y muy significativa. Paredes era el general en turno al servicio de la reacción que, a estas alturas, ya había perdido la esperanza de encontrar su solución dentro del centralismo. El proyecto monárquico aparece ahora como la única posibilidad del proyecto que venía a padrinando Gutiérrez Estrada y al cual va a prestar su valioso concurso Lucas Alamán. La rebelión de Paredes pretendía darle cuerpo a ese proyecto,

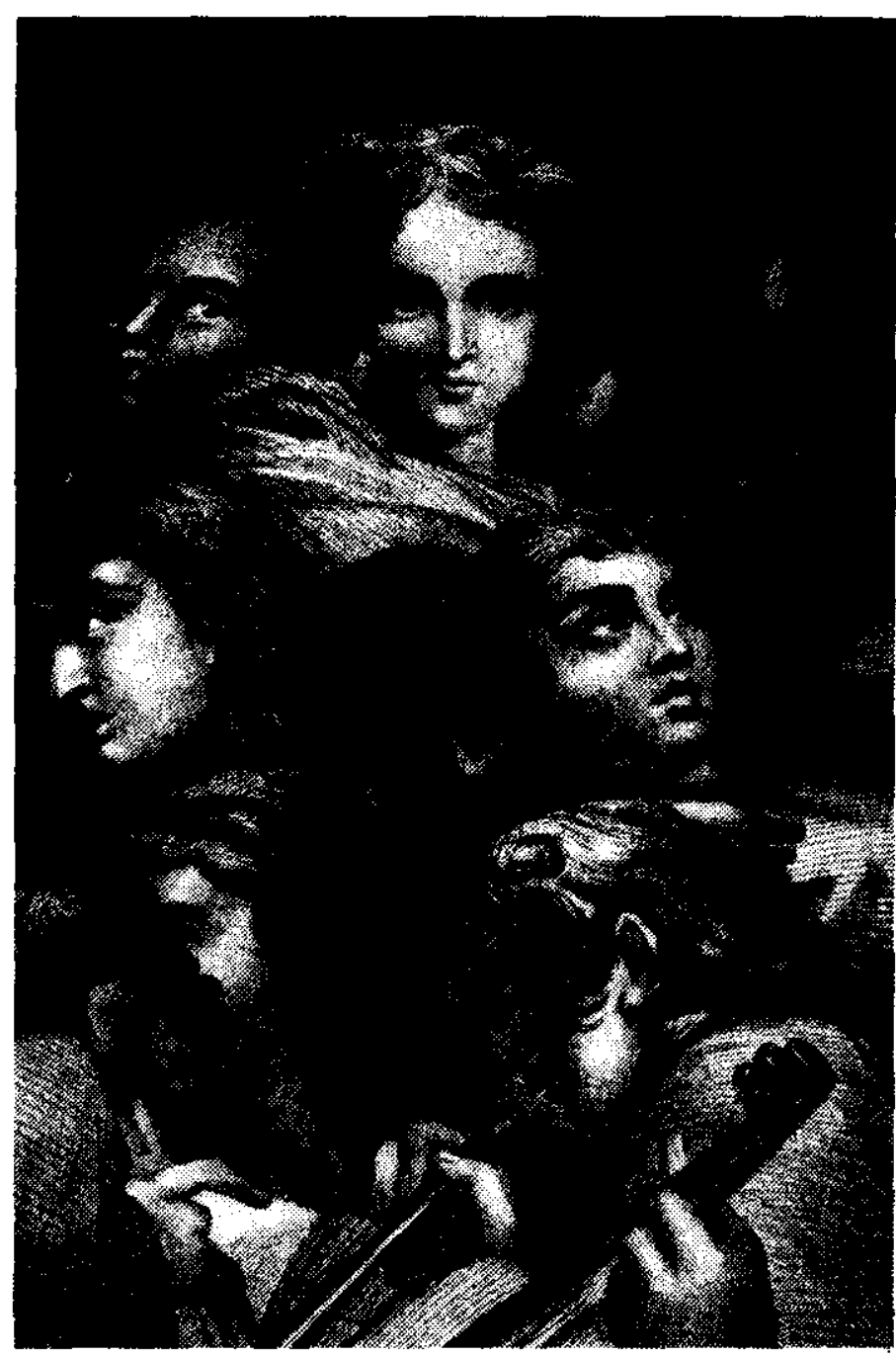

como se advierte en la ley de convocatoria (27 de enero de 1846), que fue obra del gran político reaccionario. Aquí es donde vemos la forma que cobra, con la lección de la experiencia pasada, la tendencia personalista. Es indiscutible que el proyecto monárquico de los conservadores no era un proyecto de absolutismo; era liberal y era, entendido a su modo, progresista y aun reformista. Pero su eje fue, naturalmente, la idea fundamental de encumbrar a un hombre por encima de todos, rodeándolo de un ceremonial exterior que diera satisfacción al viejo y profundo sentimiento providencialista. Y si se pensó en un príncipe extranjero, fue sobre todo con el propósito enormemente equivocado de poner un dique a la amenaza de los norteamericanos. Ésta fue, pues, la fórmula con la cual las mejores cabezas de la 
reacción, querían satisfacer las dos grandes exigencias nacionales y al mismo tiempo neutralizar los peligros exterior e interior del momento. Con una monarquía que tuviese el apoyo de las clases acomodadas de México y el de alguna potencia europea, los americanos no verían al sur como una presa fácil y por otra parte, se pondría coto a los excesos, tanto de los federalistas puros como de los candidatos a héroes nacionales. $\mathrm{El}$ individuo gozaría de garantías; el poder supremo ya no sería motivo de discordia y paulatinamente se irían realizando las reformas educativas, económicas y democráticas, queindudablemente pedía el país. Esto fue, digámoslo en honor de la verdad, lo que pretendió Maximiliano, aunque quizá no todos los mexicanos que lo rodearon.

Pero el sueño monárquico, la solución de síntesis ideada por los conservadores, no iba a ensayarse todavía. Faltaba la solución integralista de los reformistas. A ese objetivo responde la vuelta a la segunda federación. En efecto, una rebelión acabó con el poder de Paredes al grito de la traición que meditaban los conservadores con el proyecto de importar a un príncipe extranjero. El general Mariano Salas se colocó (4 de agosto de 1846) al frente del movimiento rebelde que se había iniciado en Guadalajara (20 de mayo de 1846), y aunque se trataba de un pronunciamiento federalista, los rebeldes llamaban una vez más al indispensable Santa Anna, el héroe que debería venir a aplastar a los norteamericanos. El Congreso, claroestá, lo hizo presidente (23 de diciembre de 1846); pero como los federalistas estaban en el poder, Gómez Farías fue electo vicepresidente. La administración au- torizó una legislación que atacaba directamente los bienes del clero (decreto del 11 de enero de 1847), es decir, la tendencia reformista y democrática se transformaba y ahora ensayaba una solución curiosa: pretendía emplear para el logro de sus objetivos al héroe presidencial. Este fue un error grande; pero era el primer paso hacia su propia fórmula sintética. Ante la violencia de la reacción que provocaron las disposiciones anticlericales, Santa Anna las revocó inmediatamente y prosiguió la campaña que sufrió el gran revés, si no técnico pero revés de todos modos, de Angostura. Lo más que lograron los reformistas en medio del desastre, fue implantar precariamente la federación al promulgar el Acta constitutiva y de reformas del 21 de mayo de 1847. El momento es terrible: Padierna, Churubusco, Molino del Rey, Chapultepec y el 15 de septiembre, la capital en manos del ejército enemigo. Dimite Santa Anna, pero volverá; un gobierno liberal y moderado firma las negociaciones de paz y el Tratado de Guadalupe ( 2 de febrero de 1848).

La etapa que sigue a la mutilación nacional es de gran importancia dentro de la trayectoria que vamos trazando; muestra dos aspectos fundamentales. Por una parte, el lado de la reacción tiene ya elaborado su proyecto monárquico y con Lucas Alamán como dirigente, despliega una actividad enorme para realizarlo. Se forma, coherente y vigoroso, el Partido Conservador. Los grandes propietarios, los comerciantes, los industriales, los ricos, el alto clero, forman sus filas. Por otra parte, los reformistas ocupan el poder y tratan de gobernar el país deshecho y al borde de la anarquía. La situación es aprovechada 
por los enemigos para desprestigiar al sistema federal. Lo más grave, pero curiosamente lo que va a ser decisivo para los liberales, es que el presidente no puede hacer nada efectivo: sus facultades son muy restringidas para hacer frente a las circunstancias y el Congreso y la ley misma son estorbos insuperables. Esto acarré inevitablemente la caída (6 de enero de 1853) del presidente Arista al principio de su administración. El centralismo va a volver y Santa Anna estaba a disposición para el papel que necesitaban los conservadores. Ahora Alamán le dictará sus condiciones (carta del 23 de marzo de 1853) calculadas para realizar la idea monárquica. Esto es cierto, el partido reformista con su maltrecha bandera federal parecía perdido; pero la verdad es que en ese trance y por ese trance, aprendio, por fin, la lección que habían aprendido antes y a su modo los otros. Aprendió que sin un hombre fuerte, presagio del presidente-emperador que ya está en el horizonte, no era posible, ni gobernar, ni consolidar el programa de la reforma. Y esta lección es la que va a aprovechar Comonfort en Ayutla como veremos en breve. Los reformistas iban reconociendo el trozo de verdad que tenían los conservadores y empezaban a convencerse de que era preciso contar con él para alcanzar, a su vez, su propia fórmula que integrara, dentro del ideal federalista, la dualidad de las aspiraciones populares.

A virtud del Plan del Hospicio (20 de octubre de 1852) y de unos convenios que le siguieron muy de cerca, fue declarado presidente Santa Anna el 17 de marzo de 1853. Gobernaría conforme a unas Bases para la administración de la república (22 de abril de 1853), hasta que se promulgara la Constitución nueva. Ahora no es ni centralismo, ni federación; es un gobierno de camarilla que prepara la implantación monárquica según la habían soñado Alamán y su partido. La muerte de Alamán dejó a Santa Anna con manos libres; es el momento en que se acerca más a ser un rey; es el momento, sin embargo, en que tiene menor poder auténtico; es el momento, en fin, en que se proclama el Plan de Ayutla.

\section{El sentido de la revolución de Ayutla}

Llegamos, por fin, al término de nuestro recorrido. Todos sabemos cuáles fueron los sucesos inmediatos que provocó la revuelta de Ayutla. La guarnición de México adoptó su programa; Santa Anna abandona el poder, y con él, para siempre, el escenario histórico en que había desempeñado un papel tan activo. El general Juan Álvarez, presidente interino de la república con Comonfort como espada y rodeado de la plana mayor de los liberales -Ocampo, Juárez y Prieto- ocupa el poder y se inicia inmediatamente el trabajo de la reforma. Viene la supresión de los fueros eclesiásticos y la negación al clero del derecho al sufragio. Era inevitable; era el principio de la batalla propiamente reformista. Pero no nos precipitemos a aplaudir a la revolución de Ayutla como sinónimo de la reforma pura. Todavía faltan muchos sinsabores para que la fórmula intuida por Comonfort recibiera el agrément de las tendencias liberales. Nombrado presidente sustituto ( 8 de diciembre de 


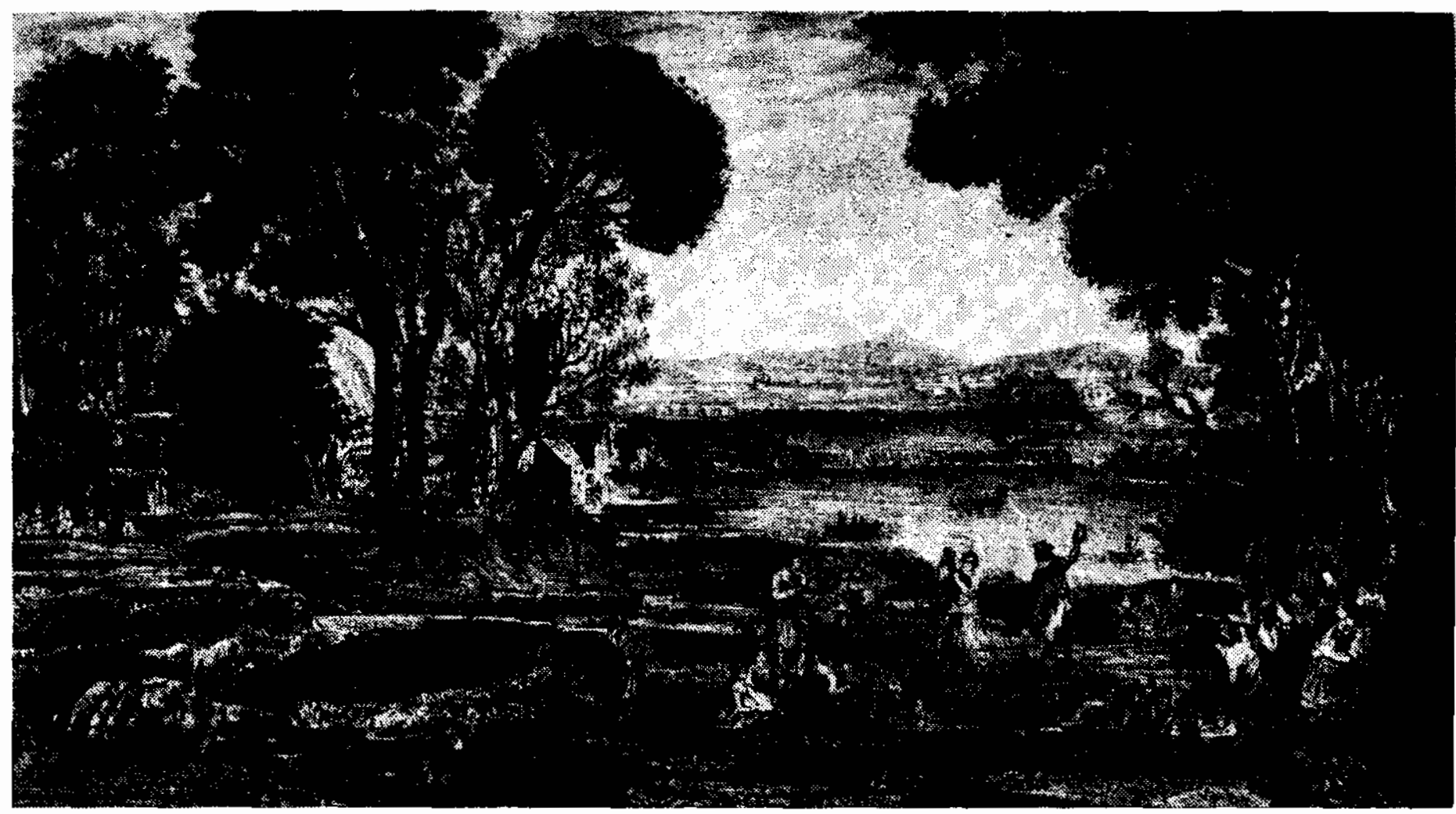

1855), sólo piensa en la manera de consolidar el triunfo de la revolución y de asegurar la posibilidad efectiva de realizar la reforma. Es un momento de rebeliones y de amagos. Los ataques a las temporalidades de la Iglesia habían provocado una reacción violentísima y el gobierno provisional se veía amenazado de muerte. El 17 de febrero de 1856 se instaló el nuevo constituyente convocado por el Plan de Ayutla. Era una asamblea que evidentemente no representaba toda la opinión nacional; su mayoría era del extremismo liberal que no entendía la idea fundamental de Comonfort, ni apoyaba su política moderada. El gran temor al despotismo personalista y la gran fe en los dogmas teóricos de la doctrina ilustrada de la libertad y de la igualdad naturales del hombre eran las luces del Congreso. Conforme a ellas va elaborando el nuevo código fundamental, sosteniendo una mal disimulada pugna con el presidente sustituto, depositario y defensor tenaz del poder discrecional que le había conferido la revolución.

Comonfort y sus ministros temen el resultado de las deliberaciones del Congreso. Con total independencia de la asamblea legislativa, se atreven a promulgar, como una muestra para el legislador, el Estatuto orgánico provisional (23 de mayo de 1856). Es un código político que, dejando al Congreso la decisión final acerca del sistema que habría de adoptarse, organiza cuidadosamente el poder omnímodo del ejecutivo. Es algo así como la contrapartida liberal de las Bases que promulgó el partido conservador en 1853. No es que Comonfort aspirara al santannato; bajo su administración se expide la Ley Lerdo ( 25 de junio de 1856) que decretó la desamortización de los bienes de las corporaciones y se revocó la admisión a la Compañía de Jesús (7 de junio de 1856) que Santa Anna había autorizado. Éstos eran actos que revelaban inequívocamente las tendencias del presidente. Pero es que Comonfort había aprendido 
la lección del fracaso del segundo régimen federal, y por eso intuía con evidencia la necesidad de integrar los principios democráticos en que creía, y un elemento de voluntad personal que le repugnaba. Con su Estatuto orgánico el presidente quería hacer lo que quería hacer Alamán para los conservadores: crear un poder firme y enérgico que mantuviera la paz a fin de poder introducir la fórmula deseada. La comunicación de Lafragua, el ministro de gobernación de Comonfort, que sirve de exposición de motivos al Estatuto es un documento capital para entender la situación. En él, mucho más explícitamente que en los Planes revolucionarios de Ayutla y de Acapulco, captamos el inicio del proceso sintetizador por el lado liberal. La tesis es clara: lo esencial no es el hombre fuerte; no es el príncipe demócrata de los conservadores; lo esencial es el principio democrático mismo. Las miras no son, pues, personalistas; las miras son la reforma social y el progreso. La igualdad y la legalidad son las bases de todo. Bien; pero es precisa, explica Lafragua, "la unidad del poder ejecutivo", es necesario "crear un centro de donde emanen todas las medidas que se crean convenientes para desarrollar la idea esencial de la pasada revolución" (Ayutla). El supremo magistrado tiene que mantener la suma de poder de que ahora está investido. El ministro no usa circunloquios: se trata de una dictadura, sí; pero de una dictadura necesaria, no sólo porque garantiza la paz y afronta las circunstancias del momento, sino porque es indispensable como elemento de la reforma social. Sus únicos límites son el respeto a las garantías individuales, por eso es dictadura, pero por eso no es despotismo ni tiranía. Una y otra vez vuelve el ministro sobre estas ideas; se dirige a la nación; pero es claro que le habla al Congreso que amenaza al país y compromete el movimiento con una constitución reformista utópica. Comonfort y su grupo han comprendido lo que más tarde dirá el maestro Justo Sierra, que las dictaduras "pueden ser detestables en teoría, pero las teorías pertenecen a la historia del pensamiento político, no a la historia política, que sólo puede generalizar científicamente sobre los hechos". El Congreso no escuchó el consejo, como Santa Anna no había querido escuchar el dictamen de Couto, acerca de la necesidad de convertir a su gobierno personalista en una administración constitucional de tendencias liberales. Santa Anna siguió jugando a ser rey y privó a la reacción de su oportunidad más brillante; el Congreso promulgó una constitución federal utópica, la del 5 de febrero de 1857 , que convirtió al ejecutivo en una especie de engranaje del legislativo por las excesivas limitaciones que se le impusieron. Surge, pues, en el momento más inoportuno, la vieja solución de la desconfianza excesiva en el hombre y de la confianza extrema en los sistemas. El código del 57 es una obra por muchos conceptos admirable: le concede al poder judicial su función política y consagra la extraordinaria novedad del juicio de amparo; pero sea lo que fuere, no se diga que es hijo de la revolución de Ayutla: en la organización general que le dio al poder públicoes contrario al espíritu de aquella revolución. Así como el santannismo del 53. fue el último destello del providencialismo puro, así la Constitución del 57 fue el postrer ensayo purista de la ten- 
dẻncia democrática. Por ese motivo merece, si se quiere, nuestra reverencia; pero lo cierto es que no era ya el año de 1824 y que la historia no había transcurridoen vano. Comonfort, tímido y bueno, se vio comprometido en el golpe de Estado (Plan de Tacubaya, 17 de diciembre de 1857) que le devolvió el poder discrecional que creía justificado, pero que tan pronto le costó el destierro. Todavía falta mucho para que los liberales se traguen la necesidad de una dictadura constitucional republicana. Falta la guerra de los tres años; falta la intervención francesa y el imperio; falta la reconquista hasta que, por fin, se extiende el largo periodo del porfirismo que, con su fórmula de "facultades extraordinarias", convierte al supremo magistrado en ese presidente-emperador de los retratos que todos conocemos, polvosos emigrados de los salones a las bodegas de los empeños y a los puestos de La Lagunilla.

La situación creada por la dictadura porfirista abre un novísimo capítulo del acontecer nacional; pero fue una situación que sobrevivió sus premisas y su razón histórica, circunstancia donde cobra su necesidad, es decir, su sentido, la revolución de 1910. Bien visto, sólo cien años son poquísimos para que un proceso tan complejo y tan internamente hendido como el de nuestra historia, haya alcanzado la solución de sus contrarios en el triunfo final del liberalismo mexicano y haya, incluso, iniciado nuevos derroteros. Esta consideración impone su optimismo al negro cuadro que actualmente pintan la miopía hermenéutica o la mala fe de los inversionistas, de los intervencionistas y de los reaccionarios. Éstos, sobre todo, no tienen perdón, porque reniegan del honroso papel de los vencidos en una lucha en que, en definitiva, también triunfaron. Pero ¿cuáles, se preguntará, son los nuevos derroteros? La cuestión excede los propósitos de este estudio. Una cosa, sin embargo, parece clara: que el viejo providencialismo se fue transformando en presidencialismo y que el viejo utopismo político ha derivado más y más hacia la economía y los problemas contemporáneos de justicia social. Si acaso todavía es lícito emplear la palabra progreso, he ahí un progreso notable. El nuevo diálogo está en pie y por fortuna no en pie de rebelión y ese es otro progreso notable.

Pongamos, pues, fin a estas meditaciones, a esta toma de conciencia histórica suscitada por la conmemoración de Ayutla, contestando en definitiva la pregunta por el sentido de esa revolución. Una conclusión parece imponerse: el vínculo entre Comonfort y Porfirio Díaz es tan claro como estrecho. Todo lo censurable que quizá nos resulte el prolongado periodo de las reelecciones porfiristas; todo lo antipático que pueda parecernos esa época victoriana de México; esa dictadura por antonomasia de nuestra historia, es, y ya conviene reconocerlo, la síntesis y liquidación y por eso la superación del gran diálogo entre los utopismos mesiánico-providencialista y teleológico-democrático que ya estaban en el "grito" de Hidalgo. Ese es su sentido profundo y positivo; es, pues, también, la significación que tuvo el movimiento de Ayutla: hacer posible la reforma, sí; pero hacerla de veras posible; es decir, no contra la historia, digámoslo así, sino con la historia. 